\title{
ESTRUTURA DIAMÉTRICA DE UMA FLORESTA TROPICAL SOB DIFERENTES FORMAS DE MANEJO
}

\author{
KÁTIA GEÓRGIA COSTA GONÇALVES
}

Engenheiro Florestal

Orientador: Prof. Dr. JOÃO LUÍS FERREIRA BATISTA

\begin{abstract}
Dissertação apresentada à Escola Superior de Agricultura "Luiz de Queiroz", Universidade de São Paulo, para a obtenção do título de Mestre em Ciências, Área de Concentração: Ciências Florestais.
\end{abstract}

P I R A C I C A B A

Estado de São Paulo - Brasil

Outubro -1999 


\section{Errata}

$\mathrm{Na}$ página 7 , no $\S 2^{\circ}$, lê-se Cohen (1965) apresentou estimadores dos parâmetros da distribuição Weibull 2-parâmetros para o método de máxima verossimilhança, em vez de Cohen (1965) apresentou estimadores da distribuição Weibull 2-parâmetros.

$\mathrm{Na}$ página 8 , equação 10 , lê-se $\hat{\alpha}_{3}=\frac{n \sum_{i=1}^{n}\left(x_{t}-\bar{x}\right)^{3}}{(n-1)(n-2) S^{3}} \quad$ em vez de $\dot{\alpha}_{3}=\frac{n}{(n-1) *(n-2)} * \sum_{1=1}^{n}\left(x_{1}-\bar{x}\right)^{3}$.

$\mathrm{Na}$ página 8 , equação 11 , lê-se $\alpha_{3}=\frac{\Gamma_{3}-3 \Gamma_{1} \Gamma_{2}+2(\Gamma)^{3}}{\left[\Gamma_{2}-\left(\Gamma_{1}\right)^{2}\right]^{\frac{3}{2}}}$ em vez de $\alpha=\frac{\Gamma_{3}-3 \Gamma_{1} \Gamma_{2}+2(\Gamma)^{3}}{\left[\Gamma_{2}-\left(\Gamma_{1}\right)^{2}\right]^{\frac{3}{2}}}$



Na página 10, equação 21, lê-se $\hat{c}=\frac{\ln \left[\frac{\ln \left(1-p_{1}\right)}{\ln \left(1-p_{2}\right)}\right]}{\ln \left[\frac{D A P_{p 1}-\hat{a}}{\left.D A P_{p 2}-\hat{a}\right]}\right.}$ em vez de $\hat{c}=\frac{\ln \left[\frac{\ln \left(1-p_{3}\right)}{\ln \left(1-p_{1}\right)}\right]}{\ln \left[\frac{D A P_{p^{3}}-\hat{a}}{D A P_{p 1}-\hat{a}}\right]}$.

$\mathrm{Na}$ página $37, \S 2^{\circ}$, lê-se as mudanças em floresta podem ocorrer por : corte ou morte de árvores, crescimento das árvores sobreviventes e recrutamento de árvores (Maclean, 1978) em vez de as mudanças em floresta podem ocorrer por : corte ou morte de árvores.

Na página $38, \S 1^{\circ}$, lê-se a função Weibull-2 parâmetros em vez de função Weibull 3-parâmetros.

$\mathrm{Na}$ página $41, \S 3^{\circ}$, lê-se os percentis 24 e 93 como variável dependente. As variáveis independentes são:

Na página 43 , equação 36 , lê-se $\Gamma_{k}=\Gamma\left(1+\frac{k}{\hat{c}}\right)$ em vez de $\Gamma_{k}=\Gamma\left(1+\frac{1}{c}\right)$. 
Dados Internacionais de Catalogação na Publicação (CIP) DIVISĀo DE BIBLIOTECA E DOCUMENTAÇĀO - Campus "Luiz de Queiroz"/USP

\author{
Gonçalves, Kátia Geórgia Costa \\ Estrutura diamétrica de uma floresta tropical sob diferentes formas de manejo / \\ Kátia Geórgia Costa Gonçalves. -- Piracicaba, 1999. \\ $58 \mathrm{p}$. \\ Dissertação (mestrado) - - Escola Superior de Agricultura Luiz de Queiroz, 1999. \\ Bibliografia. \\ 1. Equação de Weibull 2. Estimativa 3. Floresta tropical 4. Manejo Florestal 5. \\ Predição I. Título
}

CDD 634.90913 


\section{Dedico}

Aos que sonharam;

Aos que perderam os sonhos;

Aos que os recuperam :

Aos que acreditam nos sonhos e por meio deles são capazes de mudar a realidade. 


\section{AGRADECIMENTOS}

À Reserva Florestal de Linhares, na pessoa do Eng. Florestal Renato M. de Jesus, por disponibilizar os dados deste trabalho;

Ao Prof. João Batista pela paciência e dedicação;

À CAPES, por possibilitar este trabalho, fornecendo a bolsa de estudo;

À Nercina, minha mãe, pelo carinho, presteza e dedicação:

Aos amigos de Piracicaba, em especial Alessandra Reis, Andréa Vanini, Ariel Andrade, Carla Câmara, Cláudio Dell Menezzi, Cristiana Simão, "Samuel" e Sílvio Sá por tornarem a passagem pela cidade inesquecível;

Aos queridos amigos de Brasília, pela força e incentivo, especialmente para Alcidir Scariot, Andréa Vidal, Marcelo e Adriana Bayma. 


\section{SUMÁRIO}

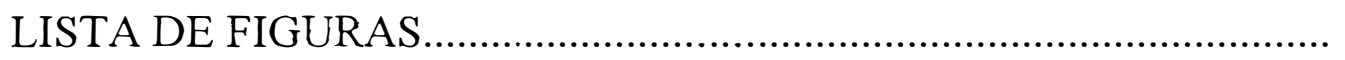

Página

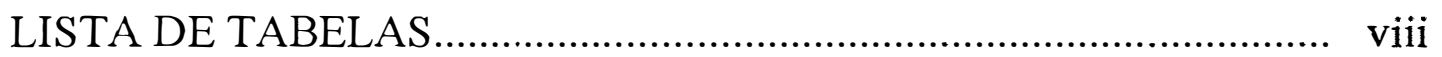

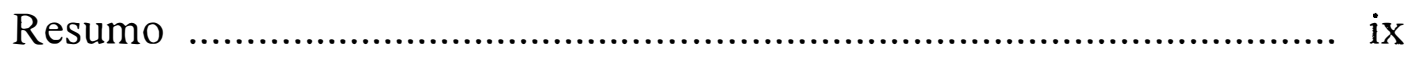

Summary

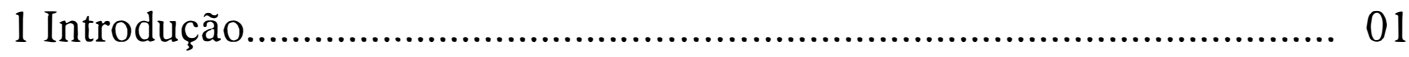



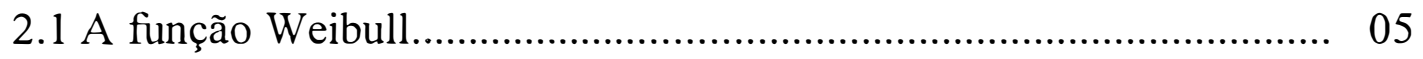

2.2 Estimadores da função Weibull........................................................ 07

2.3 Relação entre os métodos de estimação............................................... 10

2.4 Predição da estrutura diamétrica de florestas....................................... 11

3 Avaliação de cinco estimadores da função weibull utilizados para representar a estrutura diamétrica de uma floresta dissetânea tropical que sofreu cortes seletivos................................................................ 13

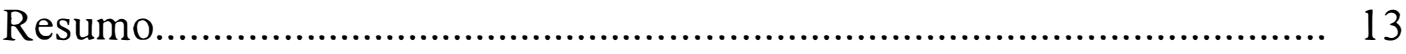

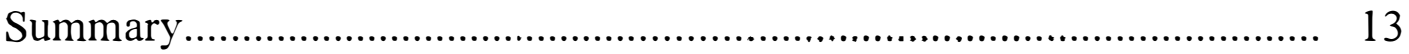

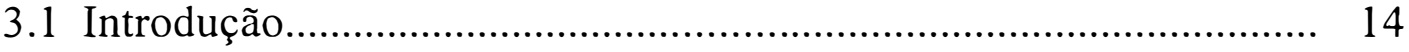

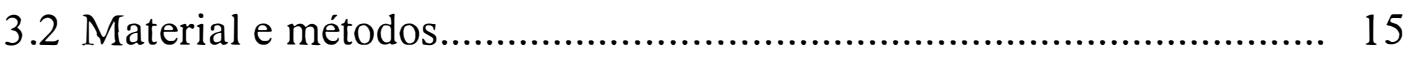

3.2.1 Breve histórico do experimento................................................. 15

3.2.2 Estimativas dos parâmetros......................................................... 17

3.2.3 Estimativas do diâmetro médio e do diâmetro médio quadrático.... 18

3.2.4 Classes de tamanho e número de indivíduos................................. 18

3.3.5 Critérios para avaliar os métodos estudados ................................ 19

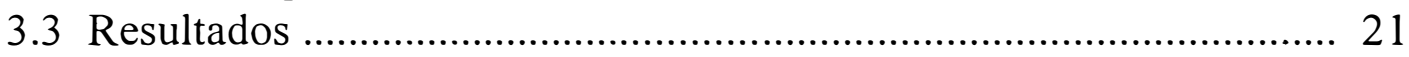

3.3.1 Performance de DADQ e DADM............................................. 21

3.3.2 Performance do DDG e DDM................................................ 23



3.3.4 Análise gráfica do ajuste da distribuição.......................................... 26

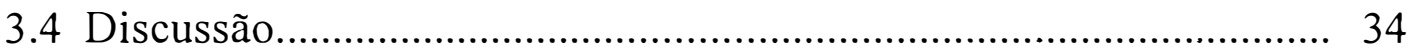

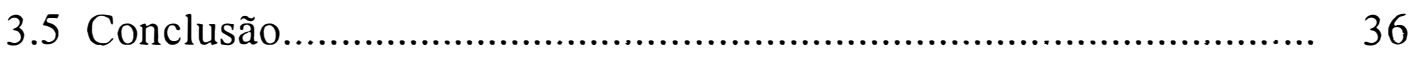


4 Avaliação de dois sistemas de estimação da estrutura diamétrica de uma floresta tropical sopb diferentes formas de manejo.

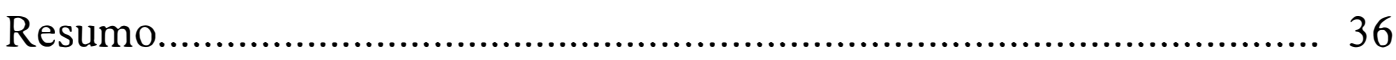

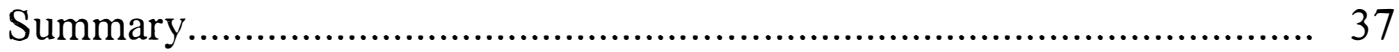



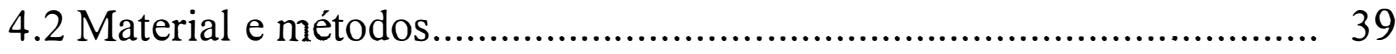

4.2.1 Breve histórico do experimento.................................................. 39

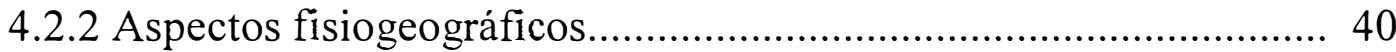

4.2.3 Aspectos climáticos................................................................. 40

4.2.4 Análises e desenvolvimento dos modelos .................................... 41

4.2.5 Avaliação dos modelos............................................................... 42

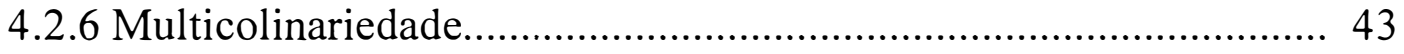



4.4.1 Modelos do sistema de Predição dos Parâmetros .......................... 43

4.4.2 Modelos do sistema de Recuperação dos Parâmetros .................... 46

4.4.3 Qualidade dos modelos desenvolvidos......................................... 49

4.4.4 Relação entre os tratamentos e os sistemas de Predição dos Parâmetros e Recuperação dos parâmetros........................................... 50

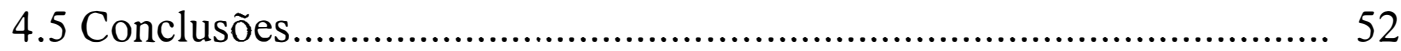

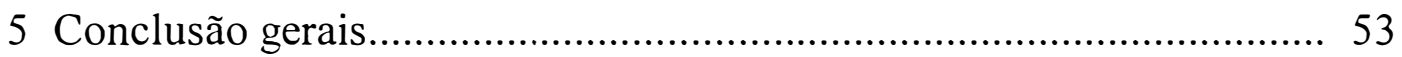

Referências bibliográficas................................................................ 55 


\section{LISTA DE FIGURAS}

1 Formas da distribuição Weibull........................................................ 06

2 Localização da Reserva Florestal de Linhares............................... 16

3 Dispersão de DDG para os cinco métodos estudados em todos os tratamentos e medições.

4 Dispersão de DDM para os cinco métodos estudados em todos os tratamentos e medições.

5 Distribuições, em classes de tamanho, dos diâmetro observados e estimados pelos cinco métodos estudados

6 Freqüências relativas acumuladas dos dados observados e estimados por cinco métodos no tratamento 1, medição 1 e 4 ........ 29

7 Freqüências relativas acumuladas dos dados observados e estimados por cinco métodos no tratamento 4 , medição 1 e 4 ....... 30

8 Freqüências relativas acumuladas dos dados observados e estimados por cinco métodos no tratamento 6 , medição 1 e 4 ........

9 Freqüências relativas acumuladas dos dados observados e estimados por cinco métodos no tratamento 7, medição 3 e 4

10 Freqüências relativas acumuladas dos dados observados e estimados por cinco métodos no tratamento 9 , medição 1 e 4 .......

11 Distribuição dos resíduos das estimativas de $\operatorname{Ln}(b)$ identificando o tratamento aplicado à floresta

12 Distribuição dos resíduos das estimativas do parâmetro de forma (c), identificando o tratamentos aplicado à floresta........................ 46

13 Distribuição dos resíduos para estimativas do percentil 24, identificando o tratamentos aplicado à floresta.............................. 48

14 Distribuição dos resíduos das estimativas do percentil 93, identificando o tratamentos aplicado à floresta 


\section{LISTA DE TABELAS}

1 DADQ e DADM dos métodos de Máxima Verossimilhança (MV), Menon (FL), Dubey (PD), Zarnakis (PZ) e Lindsay (MT) para as 23 situações estudadas

2 Valores da soma dos desvios absolutos (SADF) e o teste KS para as

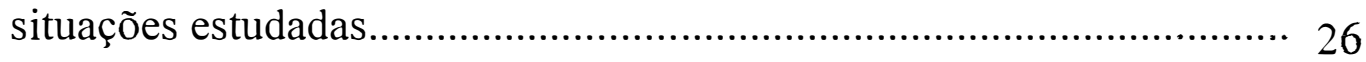

3 Modelos dos parâmetros $b$ e $c$ cujas variáveis independentes são

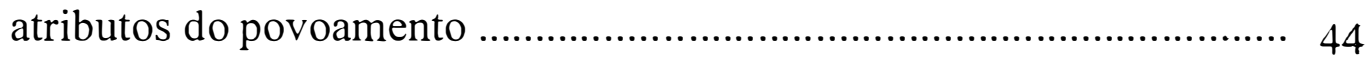

4 Modelos dos percentis 24 e 93 cujas variáveis independentes são atributos do povoamento.............................................................. 47

5 Distribuição de DDG para os métodos de Predição dos Parâmetros e Recuperação dos Parâmetros............................................................. 49

6 Distribuição de DDM para os métodos de Predição dos Parâmetros e Recuperação dos Parâmetros 


\title{
ESTRUTURA DIAMÉTRICA DE UMA FLORESTA TROPICAL SOB DIFERENTES FORMAS DE MANEJO
}

\author{
Autora: KÁTIA GEÓRGIA COSTA GONÇALVES \\ Orientador: Prof. JOÃO LUÍS FERREIRA BATISTA
}

\section{RESUMO}

O estudo da distribuição diamétrica é importante pois apresenta a amplitude dos diâmetros, mostra qual a classe onde ocorre mais árvores e permite avaliar a regeneração e recrutamento de árvores. A função Weibull tem sido usada para modelar florestas, pois é flexível e cobre formas que variam de J-invertido a formas de sino. Os objetivos deste trabalho foram avaliar cinco métodos de estimação da função Weibull e avaliar dois sistemas que modelam os parâmetros da função Weibull, quando a função representa a estrutura de uma floresta tropical que sofreu cortes seletivos. Os métodos avaliados foram: máxima verossimilhança, função linear, momentos e dois métodos de percentis. Os critérios de avaliação foram: diferença dos diâmetro médios observados e estimados; diferença absoluta dos diâmetros médios observados e estimados; diferença do diâmetro médio quadrático observado e estimado; diferença absoluta do diâmetro médio quadrático e o teste de Kolmogorov-Smirnov (KS) ao nível de significância de $5 \%$. Os resultados mostraram que o método de Máxima Verossimilhança foi o melhor para estimar a estrutura diamétrica do povoamento. Quantos aos sistemas de modelagem dos parâmetros da função Weibull, os sistemas estudados foram de predição e recuperação dos parâmetros. O método de predição dos parâmetros usou como variável dependente os parâmetros $c$ e $b$, estimados por máxima verossimilhança. O método de recuperação usou os percentis $24 \mathrm{e}$ 93 como variáveis dependente, e por meio de um sistema de equações, recuperou-se os 
parâmetros $c$ e $b$. Além das tradicionais variáveis preditoras, como densidade e tempo após o corte, utilizou-se neste trabalho variáveis que exprimem a diversidade das florestas tropicais. Dentro dos critérios de avaliação, destacaram-se o teste KS, diferença dos diâmetros médio observados e estimados e diferença dos diâmetros médios quadráticos observados e estimados. Os resultados mostraram que o sistema de Recuperação dos Parâmetros foi ligeiramente superior ao de Predição dos Parâmetros.

\title{
DIAMETER STRUCTURE OF A TROPICAL FOREST UNDER DIFFERENT MANAGEMENT SYSTEMS
}

\author{
Author: KÁTIA GEÓRGIA COSTA GONÇALVES \\ Adviser: Prof. JOÃO LUÍS FERREIRA BATISTA
}

\section{SUMMARY}

The diameter distribution is important for presenting the range of diameters, showing the diameter class with higher tree abundance and for allowing estimates of tree regeneration and recruitment. The Weibull function has been used for forest modeling because it is flexible and covers from the inverted- $J$ to the bell distributions. The objectives of this study were to evaluate five methods to estimate the Weibull function and to evaluate two systems which models the parameters of the Weibull function when this function represents the structure of a tropical forest which has under different management systems. The methods evaluated were: maximum likelihood, linear function, momentum, and two methods using percentiles. The evaluation criteria used were: differences of observed and estimated mean diameters; absolute difference of observed and estimated mean diameters; differences of observed and estimated quadratic mean diameters: absolute difference of quadratic mean diameters; and the Kolmogorov-Smirnov (KS) test at the $5 \%$ significance level. The maximum likelihood method 
was the best to estimate the diametric structure of the studied forest. The systems of study were parameter prediction and parameter recovery. The "parameter prediction" method used as dependent variable the scale parameter $(b)$ and shape parameter $(c)$, estimated by the maximum likelihood method. The "parameter recovery", method used as dependent variables the percentiles 24 and 93 and, using equations, recovered the parameter $c$ and $b$ of the Weibull function. In this work, besides the traditional predictive variables, like density and time, variables expressing the diversity of tropical forests were also used. Among the evaluation criteria, the most important were the KS test, the differences of observed and estimated mean diameters, and the differences of observed and estimated quadratic mean diameters. The results indicate that the parameter recovery method was slightly superior to the parameter prediction method. 


\section{1- INTRODUÇÃO}

Vegetação é a soma total de plantas que cobre uma área; a estrutura e a dinâmica da vegetação são resultados da interação de numerosos fatores. O efeito das plantas sobre o local onde elas vivem e sobre as outras plantas são especialmente significantes (Felfili 1993, citando Weaver \& Clements).

Um dos fatores que é responsável pela produção de um povoamento é o tratamento aplicado à floresta. O desbaste é o que mais influência a eficiência da produção de um povoamento, pois, possibilita a melhoria das condições locais para as árvores remanescentes (fornecimento de luz, nutrientes, água). Como desbaste, entende-se o corte de árvores, a partir do fechamento do povoamento, exceto cortes finais e regenerativos (Burger, 1980).

As florestas tropicais são caracterizadas pela alta densidade de plantas e pela grande diversidade de espécie cujos ritmos de crescimento são em geral diferentes (Garcia 1990). A distribuição diamétrica destas florestas tem a forma de J-investido (Meyer \& Stevenson, 1943) que é uma distribuição típica de comunidades que se auto regeneram, onde as árvores pequenas representam a grande maioria da população (Haper, 1977).

No final do século XIX, o francês De Liocourt observou que a razão do número de árvores em classe diamétrica sucessivas nas florestas dissetâneas forma uma taxa de progressão geométrica (q). Meyer introduziu o termo "floresta balanceada" para expressar florestas que mantêm a taxa de progressão constante (Scolforo, 1995). As distribuições diamétricas tropicais e sem distúrbios tendem ao equilíbrio, mas, elas não têm uma estrutura perfeitamente balanceada, com a taxa de progressão constante em todas as classes de tamanho (Haper, 1982 e Scolforo, 1995). Em uma mata de galeria do Brasil central, Felfili (1993) verificou que o valor de $q$ foi constante para as classes abaixo de $45 \mathrm{~cm}$. Esta faixa compreendeu a maioria dos indivíduos e espécies da comunidade. Acima da classe de $45 \mathrm{~cm}$, o valor de $q$ apresentou alta variabilidade, pois as classes eram compostas por poucos indivíduos. 
A distribuição diamétrica é importante em florestas dissetâneas pois permite inferir sobre: amplitude dos diâmetros, mostra as classes onde ocorrem maiores concentrações de árvores, distingue diferentes tipos florestais, possibilita a elaboração de tabela de produção considerando a dinâmica populacional e mostra o estoque (Scolforo, 1995). É possível também, relacionar o diâmetro ao planejamento do uso dos produtos extraídos da floresta e de exploração. Segundo Campus \& Turnbull (1981), a estimativa da produção florestal, associada aos dados de custo de manejo e custo da madeira, é essencial à elaboração de um plano de manejo florestal.

Para elaborar um plano de manejo em uma floresta tropical, Araujo (1993) estudou a idade relativa das árvores e o tempo de passagem determinando o ciclo de corte em povoamentos, submetidos a diferentes níveis de interferência. Para este autor, o ciclo de corte baseado no tempo passagem da classe diamétrica anterior à de cortabilidade depende: do grupo de espécies consideradas; do diâmetro mínimo de corte fixado segundo o objetivo do manejo; das mudanças nas taxas de incremento em diâmetro resultantes do nível de estoque crescimento e dos tratamentos silviculturais aplicados. O plano de colheita não pode basear-se apenas na determinação do ciclo de corte. E necessário outras informações como a curva de distribuição diamétrica balanceada para verificar as espécies que estão déficit ou superaficit.

Saraiva (1988) estudou o manejo de matas naturais mista pela distribuição diamétrica na "Mata da prefeitura", situada no município de Viçosa. Esse método consiste em manejar a estrutura da floresta de forma que é mantido a progressão contínua das freqüências, entre as classes diamétricas adjacentes. Os parâmetros que o autor utilizou foram: área basal por hectare remanescente, quociente $q$ e o valor diamétrico máximo desejado. Este autor concluiu que o método apresenta orientação bastante precisa na determinação do número de árvores, volume ou área por hectare que podem ser cortados nas diferentes classes de diâmetro, eliminando o caracter subjetivo.

Entretanto, a modelagem da distribuição diamétrica é a maneira mais fácil para providenciar informações precisas sobre a estrutura do povoamento. Os modelos são bem correlacionados com altura e volume, podem ser expressos como função das mensurações do povoamento como idade, índice de sítio, densidade e tratamentos silviculturais (Silva, 1986).

Caracterizar a estrutura de uma floresta, significa descrever matematicamente a forma da distribuição das árvores como função do DAP (Meyer \& Stevenson, 1943). Um exemplo da caracterização matemática da estrutura diamétrica de um floresta dissetânea é dado 
por Meyer (Zeide, 1984). Seguindo as idéia de De Liocourt, Meyer deduziu que o número de árvores por diamétrica é uma função exponencial negativa do ponto central da classe diamétrica:

$$
n_{i}=k e^{-a D i} \quad, \mathrm{a}>0
$$

onde: $n_{l}$ é o número de árvores na ienéssima classe diamétrica;

$k$ e $a$ são constantes do povoamento e

$\mathrm{D}_{l}$ é o ponto central da ienéssima classe diamétrica.

Segundo Meyer e Stevenson (1943), existe uma relação entre o coeficiente $a$ e a taxa de progressão:

$$
q=e^{a h}
$$

onde h é amplitude da classe diamétrica.

Bailey \& Dell (1973) introduziram a função Weibull para descrever distribuições diamétricas em florestas. Esta função é flexível, cobre varias formas de distribuições unimodais. Embora existam trabalhos que utilizam funções probabilísticas em florestas tropicais (Barros et al., 1981 e Batista, 1989) não foram encontradas referências da modelagem da função Weibull em florestas tropicais que sofram cortes seletivos.

O objetivo deste trabalho foi analisar a capacidade da distribuição Weibull em modelar a estrutura de povoamentos de floresta tropical sob condições naturais e sob diferentes condições de manejo. Foram estabelecidos dois objetivos específicos:

1) avaliar a eficiência de cinco estimadores da função Weibull em povoamentos de floresta tropical sob diferentes regimes de manejo. O regime de manejo pode alterar a estrutura diamétrica, e consequentemente, pode influenciar os parâmetros da distribuição Weibull;

2) modelar a variação da distribuição dos povoamentos em função do tempo, das variáveis próprias do povoamento e do regime de manejo aplicado. além das variáveis preditoras tradicionais, como densidade e área basal, foram utilizados índices que expressam a diversidade das espécies em cada 
tratamento. Para o estudo, foram utilizados dois sistemas de modelagem da função Weibull: predição dos parâmetros e recuperação dos parâmetros. 


\section{REVISÃO BIBLIOGRÁFICA}

\subsection{A função Weibull}

A distribuição diamétrica é o fator mais potente e simples para descrever as propriedades de um povoamento florestal. A quantificação da distribuição diamétrica e a sua relação com o sítio. composição do povoamento, idade e densidade são freqüentemente variáveis importantes em estudos de ordem econômicas e biológicas (Bailey \& Dell, 1973). As informações geradas pelo estudo de distribuição diamétrica são ferramentas básicas para se propor formas de manejo florestal (Alder, 1995).

Bailey \& Dell (1973) introduziram a função Weibull em estudos de distribuição diamétrica. A função possui 3 parâmetros. O parâmetro $a$ é chamado de parâmetro de posição. Esse parâmetro indica a posição inicial da distribuição. Quando $a=0$, a distribuição inicia- se na origem e a função transforma-se na Weibull 2-parâmetros. $O$ parâmetro $b$ controla as dimensões que a curva assume, ou seja, a dispersão dos dados. O parâmetro $c$ controla a forma da distribuição (Bailey \& Dell, 1973; Clutter et al., 1983 e Batista, 1989). A função de densidade probabilística Weibull 2-parâmetros e a função de densidade probabilística Weibull 3parâmetros são expressas, respectivamente, por:

$$
\begin{aligned}
& f(x)=\frac{c}{b}\left(\frac{x}{b}\right)^{c-1} \exp \left[-\left(\frac{x}{b}\right)^{c}\right] \text { para } x \geq 0 ; b>0, a>0 \text { e } c>0 \\
& f(x)=\frac{c}{b}\left(\frac{x-a}{b}\right)^{c-1} \exp \left[-\left(\frac{x-a}{b}\right)^{c}\right] \text { para } x \geq 0: b>0, \text { a }>0 \text { e } c>0
\end{aligned}
$$






Figura 1- Formas que a distribuição Weibull pode adquirir

A função Weibull cobre formas de distribuição que variam da forma de J-invertido a distribuições que possuem formas de sino, sendo que estas últimas podem variar em graus de simetria (Figura 1).

Destacam-se como qualidade da função Weibull a flexibilidade e a capacidade de descrever distribuições contínuas unimodais (Bailey \& Dell, 1973; Shiver, 1985 e Batista, 1989). Outra qualidade da função é a fácil integração da função de densidade probabilística. Esta propriedade da função probabilística permite determinar facilmente a distribuição diamétrica, quando são conhecidos o número total de árvore e os parâmetros (Bailey, 1973; Shiver, 1985 e Scolforo, 1995). A função de densidade probabilística acumulada pode ser apresentada com 2 ou 3 parâmetros e são expressas, respectivamente, por:

$$
F(x)=1-\exp \left[-\left(\frac{x}{b}\right)^{c}\right]
$$

ou 


$$
F(x)=1-\exp \left[-\left(\frac{x-a}{b}\right)^{c}\right]
$$

\subsection{Estimadores da função Weibull}

Embora a função Weibull possua as qualidades acima descritas, a estimação dos parâmetros apresentam diferentes níveis de dificuldades (Zarnoch \& Dell, 1985 e Lindsay et al., 1996).

Cohen (1965) apresentou estimadores da distribuição Weibull 2- parâmetros, que são expressas como:

$$
\hat{b}=\sum_{i=1}^{n}\left(\frac{x_{i}^{\hat{c}}}{n}\right)^{\frac{1}{\hat{c}}}
$$

$$
\hat{c}=\frac{n}{(1 / \hat{b})^{\hat{c}} \sum_{i=1}^{n}\left(x_{i}^{\hat{c}} \ln \left(x_{i}\right)\right)-\sum_{i=1}^{n} \ln \left(x_{i}\right)}
$$

onde: $n$ é o número de observações e $x_{i}$ é os DAPs observados.

Nessa expressões, a estimativa $b$ é função de $\hat{c}$, enquanto a estimativa $c$ é função de $\hat{b}$ e de $\hat{c}$. A solução desse sistema é obtida substituindo $\hat{b}$ em $\hat{c}$ e transformando-se para:

$$
\frac{\sum_{i=1}^{n} x_{i}^{\hat{c}} \ln \left(x_{i}\right)}{\sum_{i=1}^{n} x_{i}^{\hat{c}}}-\frac{\sum_{i=1}^{n} \ln \left(x_{i}\right)}{n}-\frac{1}{\hat{c}}=0
$$

Encontra-se $\hat{c}$ a partir de processo iterativo que pode ser pelos métodos: bisecção, ponto-fixo, Newton-Rapson ou secante (Burden \& Faires, 1985).

Lindsay et al. (1996) usaram momentos para estimar o parâmetro $c$ da função Weibull. Segundo os autores, o método proposto tem a vantagem de estimar a assimetria da distribuição, que é expressa como: 


$$
\hat{\alpha}_{3}=\frac{n}{(n-1)^{*}(n-2)} * \frac{\sum_{i=1}^{n}\left(x_{1}-\bar{x}\right)^{3}}{S^{3}}
$$

onde: $\bar{x}$ é a média dos DAPs e

S é o desvio padrão.

A partir do conhecimento do valor da assimetria, estima-se $c$ através de métodos iterativos:

$\alpha=\frac{\Gamma_{3}-3 \Gamma_{1} \Gamma_{2}+2(\Gamma)^{3}}{\left[\Gamma_{2}-\left(\Gamma_{1}\right)^{2}\right]^{\frac{3}{2}}}$

onde : $\Gamma_{k}=\Gamma\left(1+\frac{k}{c}\right)$ é a função gama.

Após ter estimado $c$ a estimação dos parâmetros $b$ e $a$ são expressos por:

$$
\hat{b}=\left(\frac{S}{\left(1+\frac{2}{c}\right)-2\left(1+\frac{1}{c}\right)}\right)^{\frac{1}{2}}
$$

E o parâmetro $a$ é estimado através da expressão:

$$
\hat{a}=\bar{x}-\hat{b} \Gamma_{1}
$$

Menon (1963) usou função linear para estimar a distribuição Weibull 2parâmetros. Para a estimativa dos parâmetros $\hat{b}$ quando $\hat{c}$ desconhecidos, foram usadas as seguintes expressões: 


$$
\begin{aligned}
& \hat{c}=\frac{1}{\left\{\left(6 / \pi^{2}\right)\left[\sum_{i=1}^{n}\left(\ln x_{i}\right)^{2}-\left(\sum_{i=1}^{n} \ln x_{i}\right)^{2} / n\right] /(n-1)\right\}^{\frac{1}{2}}} \\
& \hat{\ln b}=\left(\sum_{i=1}^{n} \ln x_{i}\right) / n-\lambda_{1} * \frac{1}{\hat{c}} \\
& \hat{b}=\exp (\ln b)
\end{aligned}
$$

onde: $\lambda_{1}=-0,5772$;

$$
\begin{aligned}
& \pi \text { é o número } \mathrm{pi}=3,1415 \text {; } \\
& \text { In representa o logaritmo neperiano e } \\
& \text { exp representa exponencial na base natural. }
\end{aligned}
$$

Dubey (1967) introduziu o método dos percentis para a estimativa da distribuição Weibull dois parâmetros. No método desenvolvido por esse autor, a variância dos parâmetros é função das probabilidades. As melhores probabilidades para estimar os parâmetros da distribuição são as que minimizam a variância das estimativas. Por meio de processos computacionais, esse autor verificou que as probabilidades que minimizam a variância do parâmetro $\hat{c}$, quando $b$ e $c$ são desconhecidos, são 0,16730679 e 0,97366352 . Sendo assim, os percentis 16,7 e 97,3 são os melhores percentis para a estimativa $\hat{c}$ quando não se conhece $b$ e $c$. Para essa situação, os estimadores de Dubey (1968) para Weibull dois parâmetros são:

$$
\begin{aligned}
& \hat{c}=\frac{\ln \left(-\ln \left(1-p_{1}\right)\right)-\ln \left(-\ln \left(1-p_{2}\right)\right)}{\ln D A P_{p 1}-\ln D A P_{p 2}} \\
& \hat{b}=\exp \left[\frac{1}{2} \sum_{i=1}^{2}\left\{\ln \left(D A P_{p_{1}}\right)-\ln \left(-\ln \left(1-p_{1}\right)\right) / \hat{c}\right\}\right] \\
& \text { onde: } p_{1} \text { e } p_{2} \text { são probabilidades }\left(p_{1}=0,167 \text { e } p_{2}=0,974\right) ;
\end{aligned}
$$

DAP $_{\mathrm{p} 1}$ e DAP 2 são os percentis da distribuição; 
In indica logaritmo neperiano e

exp representa exponencial na base natural.

Zanakis citado por Zarnoch \& Dell (1985) propôs a estimativa para a Weibull 3parâmetros baseados em três percentis, relativos às probabilidades $p 1=0,167, p 2=0,63$ e $p 3=$ 0,974 .

$$
\begin{aligned}
& \hat{a}=\frac{x_{p 1} x_{p 3}-x_{p 2}^{2}}{x_{p 1}+x_{p 3}-2 x_{p 2}} \text { se } a \text { for diferente de zero } \\
& \hat{a}=x_{1} \text { nos demais casos. }
\end{aligned}
$$

Utilizando a propriedade da Weibull que $\mathrm{x}_{\mathrm{p}}=a+b$ é aproximadamente o percentil relativo a $\mathrm{p}=0,63$ (Bailey \& Dell, 1973 e Batista, 1989) o estimador $b$ proposto foi:

$$
\hat{b}=x_{\mathrm{p} 2}-\hat{a}
$$

O estimador $c$ foi o mesmo proposto por Dubey (1967), mas substituindo $\mathrm{DAP}_{p 1}$ por $\left(\mathrm{DAP}_{p 1-}-a\right)$, como a seguir:

$$
\hat{c}=\frac{\ln \left[\ln \left(1-p_{3}\right)\right]}{\ln \left[\frac{D A P_{p:}-\hat{a}}{D A P_{n+1}-\hat{a}}\right]}
$$

\section{3 Relação entre os métolos de estimação}

As estimativas dos parâmetros pelo método de Máxima Verossimilhança são consideradas estatisticamente melhores porque apresentam menores variâncias e as estimativas de viés são baixas (Shiver, 1985). Para Bailey \& Dell (1973) o método de Máxima Verosimilhança é a melhor escolha para se estimar os parâmetro da Weibull, quando a amostra é grande. Quando a amostra é pequena, para se utilizar esse método, é necessária a correção do 
viés. Scolforo (1995) afirma que Máxima Verosimilhança estima com auto grau de probabilidade o resultado de um conjunto de dados, se a amplitude entre o menor e o maior resultado não for grande. Um empecilho para a utilização desse método é a necessidade de utilizar algoritmos computacionais para estimar o parâmetro de forma (Bailey\& Dell, 1973 e Zarnoch \& Dell, 1985) que exigem tempo e custo (Shiver, 1985).

Para Dubey (1967), o método de Máxima Verosimilhança e dos Momentos

utilizados nas estimativas da distribuição Weibull têm a desvantagem de não estimar o parâmetro de forma explicitamente. Este autor propõe percentis para a estimação dos parâmetros da distribuição Weibull. Zarnoch \& Dell (1985) propuseram o método de Zanakis como um método alternativo ao método de Máxima Verosimilhança. Para estes autores, o método de Zanakis pode ser superior ao método de máxima verosimilhança, quando o número de observações é pequeno e o parâmetro $c$ é menor que 2 .

\subsection{Predição da estrutura diamétrica de florestas}

A predição da distribuição diamétrica de povoamentos é de grande valor para os manejadores e pesquisadores florestais (Rennolls et al., 1985), pois permite aferir sobre futuras colheitas na floresta, ou, avaliar os tratamento silviculturais aplicados nos povoamentos. O tipo de florestas, volume ou estoque podem ser obtidos a partir de inventários feitos em um instante no tempo, enquanto previsões das condições futuras dos povoamentos existentes podem ser preditas usando modelos de crescimento e produção (Soares et al., 1985). As parcelas permanentes que são mensuradas em muitas ocasiões providenciam dados para o estudo do comportamento das florestas. A utilização de métodos mais precisos, para estimar as variáveis do povoamentos, são utilizados para otimizar o uso dos recursos de florestas (Zeide, 1993).

Existem vários métodos que tentam predizer a dinâmica de povoamentos como matriz de transição (Buongiorno et al., 1995), equações diferencias (Moser, 1972) e funções probabilística (Vanclay, 1994).

É comum gerar frequiências de classes diamétricas usando funções de densidade probabilísticas . Estas funções prognosticam o número de árvore por unidade de área divididas em classe diamétricas (Kuru, 1992). A partir da distribuições de DAP, é possível determinar a 
distribuição de outras variáveis como área basal e volume. Conseqüentemente, pode-se prever os produtos que seriam produzidos pela floresta (Rennolls et al., 1985).

Em florestas plantadas, a técnica da predição da estrutura diamétrica em florestas é encontrada na literatura (Bailey \& Dell 1973; Zarnoch et al., 1991; Pienaar \& Rheney, 1993 e Scolforo \& Machado 1996). Entretanto para florestas dissetâneas, a predição da estrutura de florestas ainda é incipiente (Vanclay, 1994).

Barros et al. (1981) sugerem o uso da função Weibull como função probabilistica da distribuição de DAP, em florestas tropicais pluviais da Amazônia. Devido à grande flexibilidade, esta função apresenta ótimas possibilidades de ser usada com sucesso em florestas similares. 
3- AVALIAÇÃO DE CINCO ESTIMADORES DA FUNÇÃO WEIBULL UTILIZADOS PARA REPRESENTAR A ESTRUTURA DIAMÉTRICA DE UMA FLORESTA DISSETÂNEA TROPICAL QUE SOFREU CORTES SELETIVOS.

RESUMO

O estudo da distribuição diamétrica é importante pois apresenta a amplitude dos diâmetros, mostra qual a classe onde ocorre mais árvores e permite avaliar a regeneração e recrutamento de árvores. A função Weibull tem sido usada para modelar florestas, pois a função é flexível e cobre formas que variam de J-invertido a formas de sino. O objetivo deste trabalho foi avaliar cinco métodos de estimação da função Weibull, quando a função representa a estrutura de uma floresta tropical que sofreu cortes seletivos. Os métodos avaliados foram: máxima verossimilhança, função linear, momentos e dois métodos de percentis. Os critérios de avaliação dos métodos foram: diferença dos diâmetros médios observados e estimados; diferença absoluta dos diâmetros médios observados e estimados; diferença do diâmetro médio quadrático observado e estimado; diferença absoluta do diâmetro médio quadrático e o teste KolmogorovSmirnov (KS) ao nível de signicância de $5 \%$. Os resultados mostraram que o método de Máxima Verossimilhança foi o melhor para estimar a estrutura diamétrica do povoamento estudado.

SUMMARY

The diameter distribution is important for presenting the range of diameters, showing the diameter class with higher tree abundance and for allowing estimates of tree regeneration and recruitment. The Weibull function has been widely used for forest modeling because it is flexible and covers from the inverted-J to the bell shaped distributions. The 
objective of this study was to evaluate five methods to estimate the Weibull function when this function represents the structure of a tropical forest under different management systems. The methods evaluated were: maximum likelihood, linear function, momentum, and two methods using percentiles. The evaluation criteria used were: differences of observed and estimated mean diameters; absolute difference of observed and estimated mean diameters; differences of observed and estimated quadratic mean diameters; absolute difference of quadratic mean diameters; and the Kolmogorov-Smirnov (KS) test at the 5\% significance level. The maximum likelihood method was the best to estimate the diametric structure of the studied forest.

\subsection{INTRODUÇÃO}

Funções probabilísticas são freqüentemente usadas em estudos de distribuição diamétrica e, dentre elas, a função Weibull é bastante utilizada para descrever a estrutura diamétrica de florestas (Lindsay et al., 1996)

Bailey \& Dell (1973) introduziram a função Weibull em estudos de distribuição diamétrica. Destacam-se desta função a flexibilidade e capacidade de cobrir formas que variam de j-invertido a formas de sino. A função possui 3 parâmetros; a é chamado de parâmetro de posição, $b$ controla a dimensão que a curva assume e $c$ controla a forma da distribução, quando é igual a zero, a função torna-se Weibull dois parâmetros. A função de densidade probabilística da Weibull 3-parâmetros é:

$$
f(x)=\frac{c}{b}\left(\frac{x-a}{b}\right)^{c-1} \exp \left[-\left(\frac{x-a}{b}\right)^{c}\right] \text { para } x \geq 0 ; b>0, a>0 \text { e } c>0
$$

Outra qualidade da função Weibull é a fácil integração da função de densidade probabilística. Esta propriedade permite determinar a distribuição diamétrica, quando são conhecidos o número total de árvore e os parâmetros. A função da distribuição acumulada para Weibull 3-parâmetro é :

$$
F(x)=1-\exp \left[-\left(\frac{x-a}{b}\right)^{c}\right]
$$


Estudos de funções de distribuições diamétrica em floresta tropical são incipientes, quando comparados com os de florestas temperadas. Entre outros, Barros et al., (1981) e Batista (1989 e 1994) utilizaram a função Weibull em estudos de distribuição diamétrica em floresta tropicais. Mas ainda resta saber: 1) qual o comportamento da função, quando utilizada em florestas tropicais que sofreram corte seletivo; 2) quais métodos estimam com precisão e sem viés a distribuição diamétrica e as variáveis que descrevem o povoamento.

O objetivo desse trabalho foi avaliar cinco métodos que estimam os parâmetros da função Weibull em uma floresta tropical sob várias formas de manejo. A avaliação foi baseada na eficiência e na praticidade de cada método. Os tratamentos aplicados à floresta podem influenciar a qualidade das estimativas das variáveis que descrevem o povoamento.

\subsection{MATERIAL E MÉTODOS:}

\subsubsection{Breve histórico do experimento}

Em 1980, a Reserva Florestal de Linhares começou o estudo do comportamento de uma floresta de Mata Atlântica após o tratamento de corte seletivo. O tipo de floresta do estudo é uma mata de tabuleiro ou floresta densa uniforme. Esta vegetação é típica de floresta Atlântica de terra baixa do sul da Bahia ao norte do Espirito Santo, e representa 63,1\% da reserva de linhares (Batista, 1994). A Reserva abrange uma área de 21.787 ha, o que corresponde a $25 \%$ da cobertura vegetal remanescente atual do estado do Espírito Santo; localiza-se entre os Municípios de Linhares e São Mateus, ao norte do Estado; geograficamente, situa-se entre os paralelos $19^{\circ} 06^{\prime}$ e $19^{\circ} 19^{\prime}$ de latitude sul e os meridianos $39^{\circ} 45^{\prime}$ e $40^{\circ} 19^{\prime}$ de longitude W Gr. O acesso principal dá-se pela estrada BR-101 Norte, na altura do Km 122, (Jesus,1986; Araujo, 1993 e Batista, 1994).

O projeto foi instalado em cinco blocos e nove tratamentos (Figura 2). Cada tratamento ocupa uma área de 0,5 ha $(50 \times 100 \mathrm{~m})$, totalizando uma área de 4,5 ha para bloco e 22,5 ha para a área total do ensaio. Em 1980, as árvores com DAPs superiores a $10 \mathrm{~cm}$ foram medidas antes e depois da execução dos tratamentos (não houve a medição dos DAPs nos 
tratamento que sofreu corte raso nos períodos após o corte e três anos depois). Após a execução dos tratamentos, os DAPs foram remedidos trianualmente, Jesus (1986).

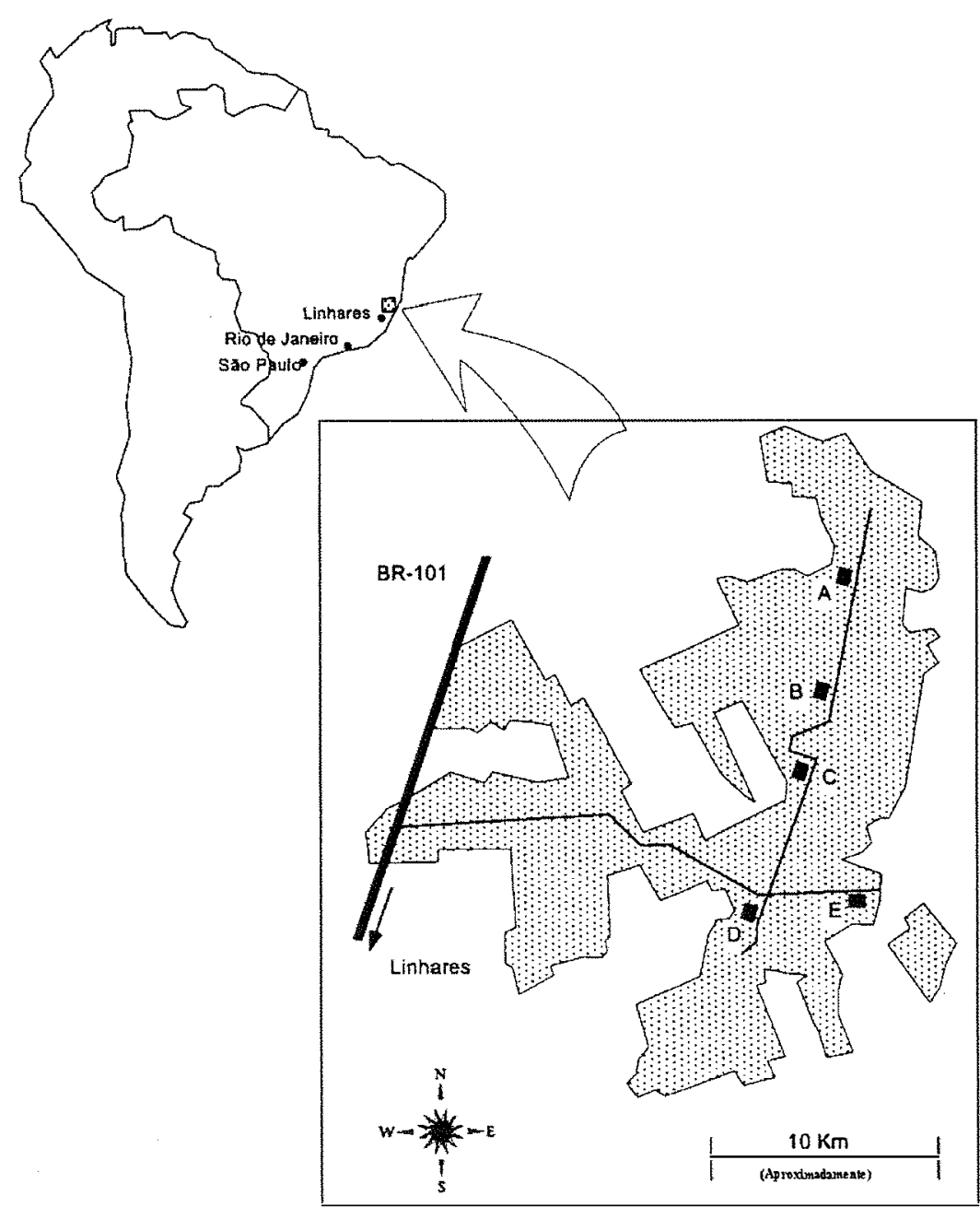

Figura 2- Localização da Reserva Florestal de Linhares, em destaque o perímetro da Reserva e as localizações dos blocos ( Fonte: Batista, 1994)

Neste trabalho, estudou-se cinco tratamentos de um bloco da reserva de Linhares, descritos abaixo:

Tratamento 1- controle, sem interferência;

Tratamento 4- corte de $45 \%$ da área basal, de modo seletivo, removendo-se as árvores de maior DAP; 
Tratamento 6 - corte de todas as árvores com DAP menor de $10 \mathrm{~cm}$ e maior de $80 \mathrm{~cm}$ seguindo o corte de $30 \%$ das remanescente em área basal, de modo seletivo, removendo-se as árvores residuais maiores;

Tratamento 7- corte raso;

Tratamento 9- corte de todas as árvores com DAP $\geq 50 \mathrm{~cm}$ seguindo o corte de $25 \%$ das remanescente em área basal, de modo seletivo, removendo as maiores árvores residuais;

Foram analisados os tratamentos medidos no ano de 1980, após o corte seletivo, e no ano de 1989. Essas medições foram referenciadas, respectivamente, como medição 1 e 4 . A exceção feita a esta situação foi o corte raso que foi analisado nos anos de 1986 e 1989, sendo referenciados como medições 3 e 4 .

\subsubsection{Estimativas dos parâmetros}

Os parâmetros da Weibull foram estimados por cinco métodos: Máxima Verossimilhança (eq. 7 e 8 ) descrito por Cohen (1965), método baseado nos momentos da distribuição (eq. 11 e 12) descrito por Lindsay et al., (1996), método de Menon (1963) que utilizou estimadores lineares (eq. 14 e 15) e dois métodos de percentis (Dubey, 1968 (eq. 17 e 18 ) e Zanakis citado por Zarnoch \& Dell, 1985 (eq. 20 e 21)). Estes métodos foram escolhidos por serem comuns nos estudos de distribuições diamétrica.

Os métodos de Máxima Verosimilhança, Momentos, Dubey e Menon estimaram os parâmetros da distribuição Weibull dois parâmetros. Para transformar a função da Weibull 3parâmetros para Weibull 2-parâmetros, Bailey \& Dell (1973) sugere a transformação da variável $D A P$ para (DAP-a). Nesse trabalho, o levantamento das espécies no campo foi truncado em 10 $\mathrm{cm}$, sendo esse valor do parâmetro $a$. Nos métodos de máxima verossimilhança e Menon, em vez de subtrair o valor dez, subtraiu-se o valor 9,9. Essa transformação foi feita porque estes métodos utilizam a soma do logaritmo neperiano dos diâmetros observados. Se utilizasse o valor do parâmetro $a$ igual a 10 , quando houvesse a transformação (DAP-a), haveria a perda dos valores logaritmos dos diâmetros iguais a $10 \mathrm{~cm}$ de diâmetro. 


\subsubsection{Estimativas do diâmetro médio e do diâmetro médio quadrático}

Os estimadores do diâmetro médio e do diâmetro médio quadrático foram baseados nos momentos da distribuição. Para a estimativa do diâmetro médio, utilizou-se da sugestão de Lindsay et al., (1996), que expressa a média como:

$$
\hat{\bar{D}}=\hat{\mathrm{a}}+\hat{\mathrm{b}} \Gamma_{1}
$$

A estimativa do diâmetro médio quadrático é baseado no segundo momento da distribuição (Batista (1989) citando Burk \& Neubery). A expressão da estimativa do diâmetro médio quadrático é:

$$
\hat{\bar{D}}_{g}=\sqrt{\hat{a}^{2}+2 \hat{a} \hat{b} \Gamma_{1}+\hat{b}^{2} \Gamma_{2}}
$$

\subsubsection{Classes de tamanho e número de indivíduos}

Para a distribuição dos indivíduos em classe de tamanho, uso-se o algoritmo de Ramsdell, descrito em Batista (1989):

$$
\begin{aligned}
& N C=1+3.33 \log _{10}(n) \\
& A=\frac{D A P_{\max }-D A P_{\min }}{N C}
\end{aligned}
$$

onde: $N C$ é o tamanho da amostra;

$n$ é o número da amostra (número de árvores);

$A$ é a amplitude das ciasses diamétrica e

$\mathrm{DAP}_{\mathrm{maz}}$ e DAP min são os diâmetros máximo e mínimo, respectivamente. 
O algoritmo de Ramsdell foi aplicado no tratamento que apresentou o maior diâmetro observado e as classes geradas pelo algoritmo foram aplicados para os outros tratamentos. A exceção foi feita ao tratamento que sofreu corte raso. Isto ocorreu porque os indivíduos desse tratamento apresentaram indivíduos menores que dos outros tratamentos, em todos os períodos. Nessa situação o algoritmo foi aplicado, considerando o maior diâmetro nas duas medições.

Bailey \& Dell (1973) demostrou como utilizar a função acumulada da distribuição Weibull para calcular o número de indivíduos por área em cada classe $(\mathbb{N})$. Supondo que $x$ é o centro de classe, a classe mede $2 w$ de largura, $N$ é o número de indivíduos observados e $N_{x}$ é o número de indivíduos por classe, então:

$$
\begin{aligned}
& N_{x}=N\{F(x+w)-F(x-w)\} \\
& N_{x}=N\left\{e^{-[(x-w) / b]^{c}}-e^{-[(x+w) / b]^{c}}\right.
\end{aligned}
$$

O cálculo da freqüência esperada em cada classe é obtida calculando a função de densidade acumulada para os limites superiores e inferiores de cada classe. Para se saber o número de indivíduos em cada classe, subtraiu-se valor da densidade acumulada do limite superior do valor da densidade acumulada do limite inferior, como mostrado na expressão 28 .

\subsubsection{Critérios para avaliar os métodos estudados}

Para se testar a qualidade de ajuste dos métodos estudados, foram utilizados os seguintes critérios: diferença dos diâmetros médios observados e estimados (DDM); diferença absoluta dos diâmetros médios observados e estimados (DADM); diferença dos diâmetros médios quadráticos observados e estimados (DDQ); diferença absoluta dos diâmetros médio quadráticos observados e estimados (DADQ); soma absoluta dos resíduos para cada classe (SADF); teste de Kolmogorov-Smirnov (KS) ao nível de significância de $5 \%$ para qualidade de ajuste (Sokal \& Rohlf, 1981) e gráfico da frequiência relativa acumulada observada e estimada por DAP. 
DDM e DDQ são medidas do viés das estimativas do diâmetro médio e do diâmetro quadrático, enquanto, DADM e DADQ são mensurações da precisão (Zutter et al., 1986). As expressões para DDM e DADM são respectivamente:

$$
\begin{gathered}
D D M=\bar{D}_{i}-\hat{\bar{D}}_{i} \\
D A D M=\left|\bar{D}_{i}-\hat{\bar{D}}\right|
\end{gathered}
$$

Onde: $\bar{D}_{i}$ é o diâmetro médio observado de cada parcela e tratamento e $\hat{\bar{D}}_{i}$ é o diâmetro médio estimado de cada parcela e tratamento.

$D D Q$ e DADQ têm definição similar, mas, usando o diâmetro médio quadrático. $S A D F$ é a mensuração da precisão do ajuste para toda a distribuição (Zutter et al. 1986), é expressa por:

$$
S A D F=\sum_{i=1}^{k}|| f_{i}-\hat{f_{i}} \mid
$$

Onde: $f_{i}$ é frequiência observada na classe $i$.

$\hat{f}_{i}$ é freqüência observada na classe $i$.

$k$ é o número de classes de diâmetro.

O teste de Kolmogorov-Smirnov (KS) de qualidade de ajuste para amostras grandes é descrito por Sokal \& Rohlf (1981). Este teste baseia-se no cálculo da diferença absoluta entre as freqüências acumuladas observadas e estimadas. No caso de se calcular a freqüência acumulada absoluta, a diferença que alcançar o valor máximo é dividida pela soma das freqüências observadas. Este valor é o valor $D$ calculado que se compara com o valor $D$ crítico. No caso de se calcular a freqüência acumulada relativa, a diferença máxima absoluta entre as distribuições observadas e estimadas é o valor $D$ calculado. O valor de $D$ crítico para amostras grandes (número de observações é maior que 100) é expresso por:

$$
D_{*}=\sqrt{\frac{-\ln \left(0,5^{*} \alpha\right)}{2 n}}
$$


Onde: $\alpha$ é o nível de significância e

$n$ é o número de observações.

\subsection{RESULTADOS}

\subsubsection{Performance de DADQ e DADM}

Conforme o tratamento aplicado à floresta, os cinco métodos apresentaram diferenças ao estimar o diâmetro médio e o diâmetro médio quadrático. Foi considerando o erro máximo aceitável $1,5 \mathrm{~cm}$ para DADQ e DADM.

No tratamento controle, tratamento 1 , o método de Zanakis não apresentou valores satisfatórios de DADQ e DADM, e o método de Menon, DADQ. No tratamento 7, corte raso, todos os métodos apresentaram resultados satisfatórios de DADQ e DADM (tabela 1).

No tratamento 6, corte das árvores com DAP menores que $10 \mathrm{~cm}$ e maiores que 80 $\mathrm{cm}$, salvo o método de Máxima Verossimilhança, todos os métodos apresentaram a tendência de obter elevado valor de DADQ e DADM.

No tratamento 4, corte de $45 \%$ da área basal, os métodos Menon, Zanakis e Lindsay não obtiveram bons resultados para DADQ e o de Lindsay para DADM.

No tratamento 9 , corte das árvores maiores que $50 \mathrm{~cm}$ mais o corte de $25 \%$ da área basal remanescente, o método de Menon não apresentou bom resultado para DADQ e Máxima verossimilhança para DADM.

Verificando a amplitude de valores de DADQ e DADM, considerando cada método, Máxima Verossimilhança apresentou o primeiro menor intervalo para DADQ e o terceiro menor intervalo para DADM. Para este método, DADQ variou entre $0,05 \mathrm{~cm}$ (tratamento 1 medição 1 ) e $1,1 \mathrm{~cm}$ (tratamento 1 medição 4). Neste método, os valores de DADM variaram entre $0,02 \mathrm{~cm}$ (tratamento 1 medição 4) e $1,37 \mathrm{~cm}$ (tratamento 9 medição 1 ). Quanto à DADM, 10\% (1) das estimativas foram maiores que $1,5 \mathrm{~cm}$.

O método de Menon apresentou o terceiro menor intervalo para DADQ e primeiro de DADM. Os valores DADQ variaram de $0,20 \mathrm{~cm}$ (tratamento 7 medição 4) a 3,02 cm (tratamentos 6 nas duas medições). Os valores de DADQ superiores a $1,5 \mathrm{~cm}$ constituíram 
$50 \%(5)$ dos casos. Neste método, DADM variou entre $0,003 \mathrm{~cm}$ (tratamento 1 medição 1 ) e 1,37 cm (tratamento 6 mediçãol).

O método de Dubey obteve as segundas menores amplitudes para DADQ e DADM. DADQ variou entre $0,08 \mathrm{~cm}$ (tratamento 4 medição 4) e 2,03 cm (tratamento 6 medição 1). Os DADQ superiores a $1,5 \mathrm{~cm}$ foram de $10 \%$ (1). Os valores de DADM variaram entre 0,02 cm (tratamento 7 medição 4) e 1,46 cm (tratamento 4 medição 1).

O método de Zanakis obteve a quarta menor amplitude para DADG e a maior amplitude para DADM. DADQ variou de 0,26 cm (tratamento 7 medição 3) a 5,91 cm (tratamento 6 medição 4), e, 40\% das DADQ foram maiores que 1,5 cm. Os valores de DADM variaram entre $0,19 \mathrm{~cm}$ (tratamento 1 medição 1) e 3,76 cm (tratamento 6 medição 4), sendo que $10 \%$ (1) das diferenças foram superiores a $1,5 \mathrm{~cm}$.

O método de Lindsay obteve a quarta menor amplitude para DADG e a maior amplitude para DADM. DADG variou entre $0,23 \mathrm{~cm}$ (tratamento 1 medição 4) e 4,93 cm (tratamento 6 medição 1), sendo que 40\% (4) das diferenças foram superiores a 1,5 cm. DADM variou entre $0,31 \mathrm{~cm}$ (tratamento 1 medição quatro) e 5,64 cm (tratamento 6 medição 1), sendo que $40 \%$ (4) das observações foram acima de $1,5 \mathrm{~cm}$. A distribuição de classificação deste método foi: $60 \%(6)$ dos casos ficaram em quinto lugar; o segundo e quarto lugares ficaram, cada, com $20 \%$ dos casos.

Das estimativas feitas para DG, 28\% (14) possuíram DADQ superiores a $1,5 \mathrm{~cm}$. A pior estimativa de DG foi feita pelo método de Zanakis $(5,91 \mathrm{~cm})$. As estimativas dos diâmetros médios foram melhores pois $18 \%$ (9) destas estimativas foram superiores a $1,5 \mathrm{~cm}$. A pior estimativa de DADM foi feita pelo método de Lindsay $(5,64 \mathrm{~cm})$. 
Tabela 1- DADQ e DADM dos métodos Máxima Verossimilhança (MV), Menon (FL), Dubey (PD), Zarnakis (PZ) e Lindsay (MT) para as situações estudadas.

\begin{tabular}{|c|c|c|c|c|c|c|c|c|c|c|c|}
\hline \multirow[b]{3}{*}{ Trat. } & \multirow[b]{3}{*}{ Med. } & \multicolumn{10}{|c|}{ Métodos } \\
\hline & & \multicolumn{2}{|c|}{ MV } & \multicolumn{2}{|c|}{$\mathrm{FL}$} & \multicolumn{2}{|c|}{ PD } & \multicolumn{2}{|c|}{$\mathrm{PZ}$} & \multicolumn{2}{|c|}{$\mathrm{MT}$} \\
\hline & & DADQ & DADM & DADQ & DADM & DADQ & DADM & DADQ & DADM & DADQ & DADM \\
\hline 1 & 1 & 0.05454 & 0.09945 & 0.24838 & 0.00321 & 0.59179 & 0.39067 & 0,35174 & 0,19209 & 0,3386 & 0,4092 \\
\hline 1 & 4 & 1,10853 & 0.02034 & 2,90628 & 0,80569 & 0,52112 & 0.49956 & 3.78478 & 1,75914 & 0,23281 & 0,31115 \\
\hline 4 & 1 & 0,95523 & 0,36714 & 1,59687 & 0,11664 & 0.21498 & 1.46698 & 2,98883 & 0.61237 & 3,43638 & 3,30768 \\
\hline 4 & 4 & 0.19872 & 0,09701 & 0,49964 & 0,26517 & 0,08531 & 0.24036 & 1,02686 & 0,91012 & 2,1853 & 2,45633 \\
\hline 6 & 1 & 0,06077 & 0,106 & 3.02269 & 1,37569 & 2,03488 & 0,99953 & 2,80051 & 1,57725 & 4,93826 & 5,64349 \\
\hline 6 & 4 & 0,25627 & 0.06451 & 3,02751 & 1,27198 & $\bullet, 17575$ & 0,40269 & 5,91091 & 3,76707 & 4,01635 & 4,66326 \\
\hline 7 & 3 & 0,12139 & 0,0883 & 0.28148 & 0,18358 & 0.57685 & 0,50914 & 0,26958 & 0,21755 & 0.36661 & 0,37525 \\
\hline 7 & 4 & 0,11971 & 0,8568 & 0.20264 & 0,90044 & 0,82322 & 0.02226 & 0,78267 & 1,37288 & 0,46098 & 1,24051 \\
\hline 9 & 1 & 0,61421 & 1,63512 & 1.94481 & 0.3726 & 0.72035 & 0.73841 & 1.29258 & 0.72703 & 0,7553 & 1,26966 \\
\hline 9 & 4 & 0,15301 & 0,06992 & 1.48361 & 0,6284 & 1,18155 & 0,9425 & 0,83138 & 0,48243 & 1,2165 & 1,35542 \\
\hline
\end{tabular}

\subsubsection{Performance do DDG e DDM}

Para DDG, os métodos Dubey e Máxima Verossimilhança apresentaram as menores dispersões, sendo que MV apresentou os menores valores extremos. Os método de Menon, Zanakis e Lindsay apresentaram as maiores dispersões. Os métodos de Zanakis e Menon apresentaram a tendência de subestimar DG, enquanto o método de Lindsay apresentou a tendência de supestimar DG (figura 3). 




Figura 3 - Dispersão de DDG para os cinco métodos estudados em todos os tratamentos e medições. (A barra branca no interior da caixa é a localização da mediana. A altura da caixa é equivalente a distância inter-quartil, ou DIQ, que representa a distância entre o $3^{\circ}$ e o $1^{\circ}$ quartil dos dados. A DIQ indica a dispersão dos dados. As linhas pontilhadas que se estendem dos extremos da caixa representam os valores extremos ou a distância 1.5 DIQ a partir do centro, a qual for menor. Os valores dos dados que caem fora da linha pontilhada são indicadas por linhas horizontais).

As distribuições das DDM, independente do tratamento e medição mostram que os métodos Máxima Verossimilhança, Menon e Dubey apresentaram os menores erros. A dispersão dos desvios é maior para os métodos de Zanakis e Lindsay, sendo que este apresentou a tendência de subestimar o diâmetro médio, e aquele, de subestimar (figura 4). 


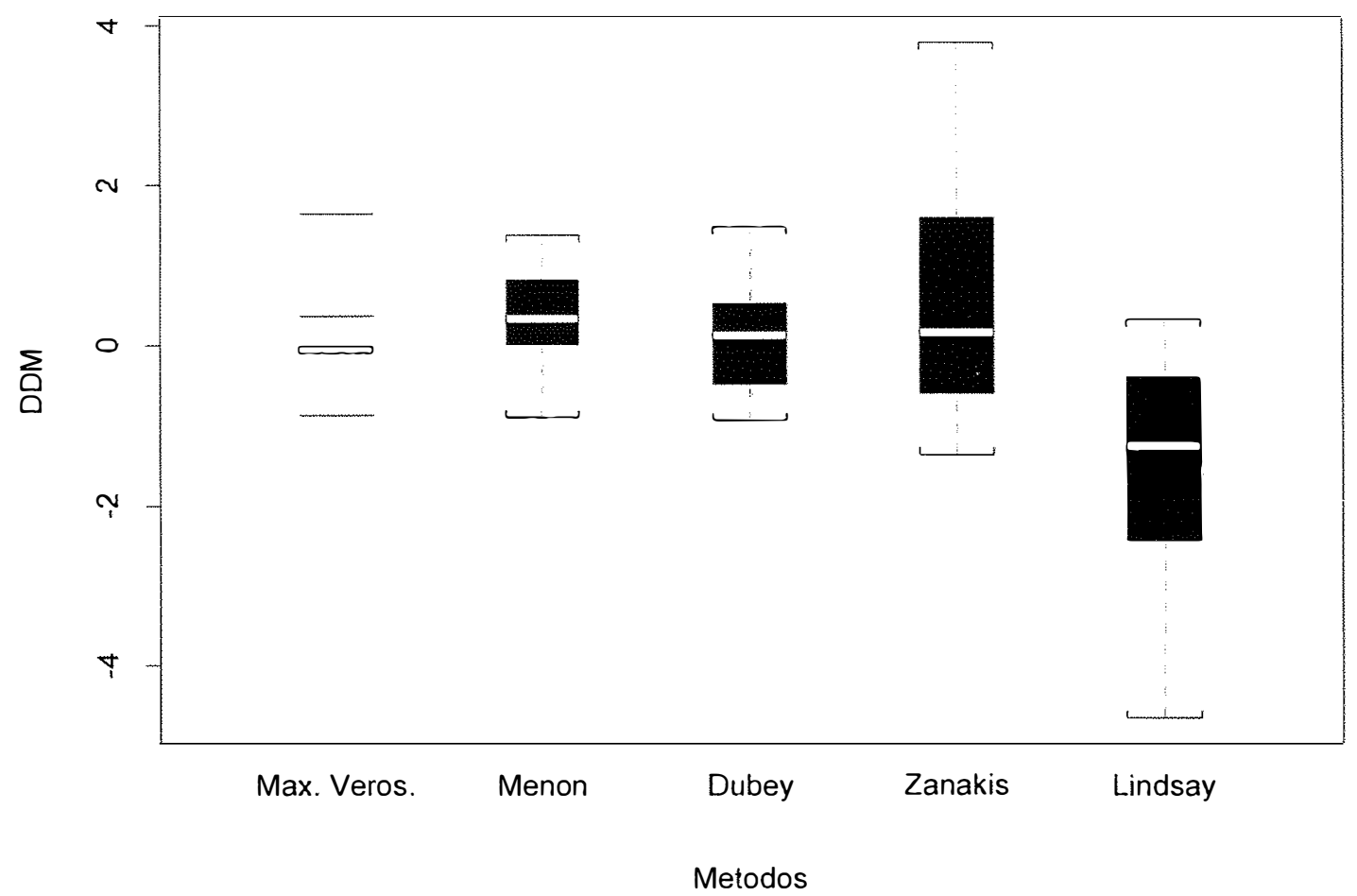

Figura 4 - Dispersão das DDM para os cinco métodos, considerando todos os tratamentos e medições

\subsubsection{Teste de aderência}

A avaliação das estimativas do número de árvore por hectare para cada método estudado foi baseada na análise gráfica da distribuição (distribuição em classes de tamanhos e relativa acumulada), soma dos desvios absolutos do número de árvores por hectare (SADF), e o teste $\mathrm{KS}$.

A figura 5 mostra a modificação da distribuição diamétrica, quando o povoamento sofreu o corte seletivo. Visualmente, o maior contraste foi notado, quando compararam-se os tratamentos 1, 4, 6 e 9 cujas distribuições são exponenciais, com o 7 cuja distribuição é assimétrica positiva. Os tratamentos 1, 4 e 9 apresentaram as curvas da distribuição mais acentuadas, quando comparadas com as curvas do tratamento 6 . 
O tratamento aplicado também influenciou a qualidade das distribuições. Visualmente, os tratamentos 1 e 9 produziram estimativas próximas das observadas, enquanto os tratamentos 4, 6 e 7 apresentaram distribuições mais heterogêneas.

Salvo tratamento 1 , as estimativas pelo método de Lindsay produziram distribuições que visivelmente são distantes das distribuições observadas. Por outro lado, os métodos de Menon e Máxima Verossimilhança produziram distribuições bem próximas das observadas.

De um modo geral, o método de Lindsay não apresentou um bom ajuste pois, com exceção feita ao tratamento 1 , todos os tratamentos apresentaram diferenças estatísticas (tabela 2). MT apresentou o maior SADF em $80 \%$ (8) dos casos. Os métodos Máxima Verossimilhança e Menon não apresentaram diferenças significativas para nenhum tratamento. Os dois métodos dos percentis apresentaram diferenças significativas em 20\% (2) dos casos.

Tabela 2- Valores da soma dos desvios absolutos (SADF) e o teste KS para as situações estudadas.

\begin{tabular}{|c|c|c|c|c|c|c|c|c|c|c|c|}
\hline \multirow{3}{*}{ Tratamento } & \multirow{3}{*}{ Medição } & \multicolumn{10}{|c|}{ Métodos } \\
\hline & & \multicolumn{2}{|c|}{ MV } & \multicolumn{2}{|c|}{ FL } & \multicolumn{2}{|l|}{ PD } & \multicolumn{2}{|c|}{$\mathrm{PZ}$} & \multicolumn{2}{|c|}{ MT } \\
\hline & & SADF & KS & SADF & KS & SADF & KS & SADF & KS & SADF & KS \\
\hline 1 & 1 & 30,88 & & 29,83 & & 37,14 & & 31,96 & & 34,08 & \\
\hline 1 & 4 & 54,25 & & 51,99 & & 65,92 & & 49,47 & & 46,03 & \\
\hline 4 & 1 & 44,89 & & 45,19 & & 74,76 & $*$ & 39,75 & & 117,66 & $*$ \\
\hline 4 & 4 & 50,19 & & 49,15 & & 43,18 & & 40,62 & & 137,07 & $*$ \\
\hline 6 & 1 & 43,06 & & 48,16 & & 42,18 & & 37,25 & & 113,66 & $*$ \\
\hline 6 & 4 & 54,42 & & 60,14 & & 62,21 & & 49,34 & $*$ & 110,91 & $*$ \\
\hline 7 & 3 & 40,83 & & 36,13 & & 41,61 & & 43,26 & & 67,39 & $*$ \\
\hline 7 & 4 & 113,05 & & 108,83 & & 133,46 & $*$ & 118,39 & * & 140,02 & * \\
\hline 9 & 1 & 36,54 & & 46,48 & & 42,48 & & 40,18 & & 61,46 & $*$ \\
\hline 9 & 4 & 45,09 & & 42,24 & & 61,47 & & 31,29 & & 80,87 & $*$ \\
\hline
\end{tabular}

* Indica diferença estatisticamente significativa para o teste de $\mathrm{KS}$ ao nível significância de $5 \%$ de probabilidade.

\subsubsection{Análise gráfica do ajuste da distribuição}

Os tratamentos aplicados à floresta podem influenciar a eficiência dos métodos que estimam os parâmetros da distribuição Weibull. A avaliação visual do tratamento 1 (fïgura 6) 
mostra que todos os métodos apresentaram boas estimativas da distribuição, pois a distribuição estimada não se distância da distribuição observada. O mesmo acontece ao tratamento 9 (figura 10), mas com a ressalva do método de Lindsay que subestimou a distribuição observada.

No tratamento 6 (figura 8), os cinco estimadores da função Weibull produziram distribuições que não acompanharam a distribuição observada tão bem quanto às produzida no tratamento 1. Neste tratamento, o método de Lindsay destaca-se por afastar da distribuição observada nas duas medições; Zanakis também distancioul-se da distribuição observada neste tratamento, na medição 4 .

Exceção feita ao método de Lindsay, quando a qualidade, as estimativas da distribuição diamétrica nos tratamentos 4 e 7 (figuras 7 e 9, respectivamente) foram intermediárias entre os tratamento 1 e 6 (figuras 6 e 8, respectivamente).

Quando as curvas estimadas da distribuição da freqüência relativa acumulada afastaram-se das curvas observadas, o teste KS apresenta diferença estatística. Este fato ratifica o teste $\mathrm{KS}$, e os gráficos da distribuição das freqüência relativa acumulada pode ser um teste prévio de qualidade de ajuste. 
tratamento 1 medicao 1

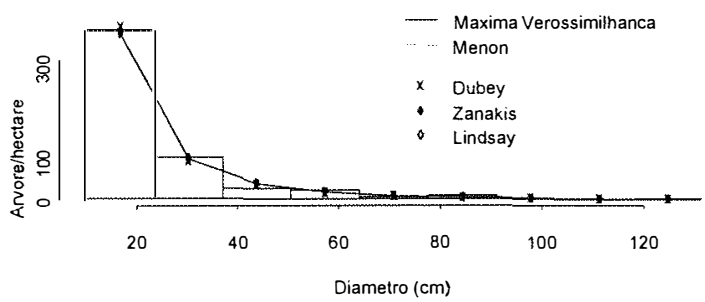

tratamento 4 medicao 1

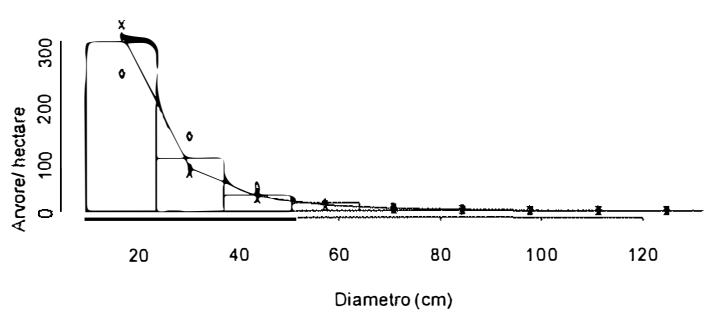

tratamento 6 medicao 1

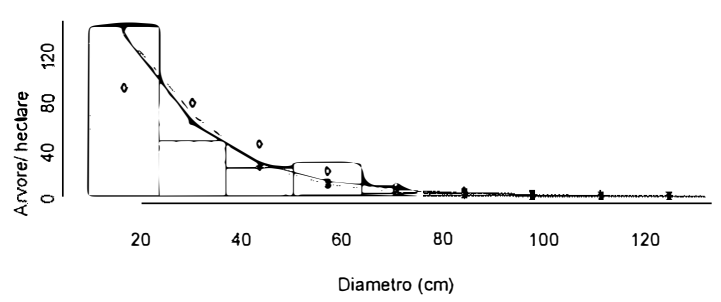

tratamento 7 medicao 3



tratamento 9 medicao 1

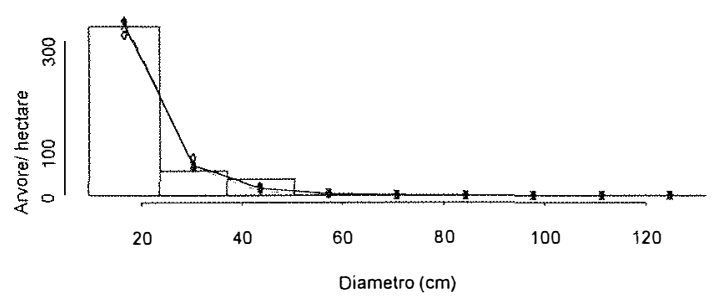

tratamento 1 medicao 4

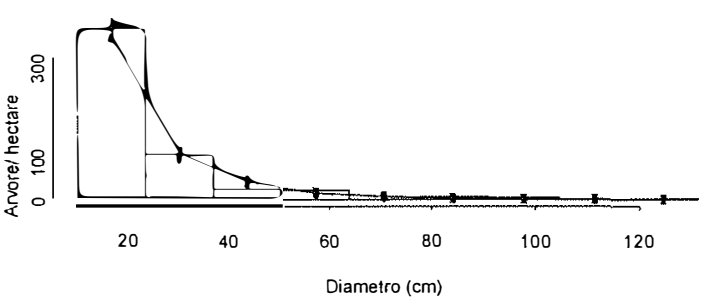

tratamento 4 medicao 4



tratamento 6 medicao 4
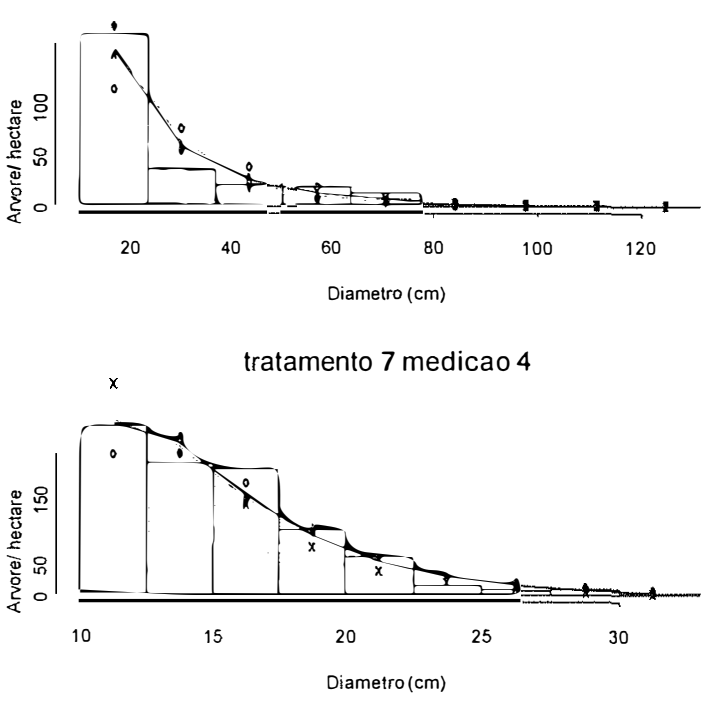

tratamento 9 medicao 4

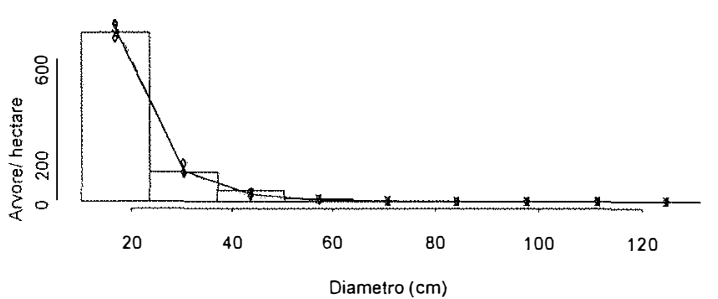

Figura 5 - Distribuição, em classes de tamanho, dos diâmetros observado e estimados pelos cinco métodos estudados. 


\section{Tratamento 1 medicao 1}

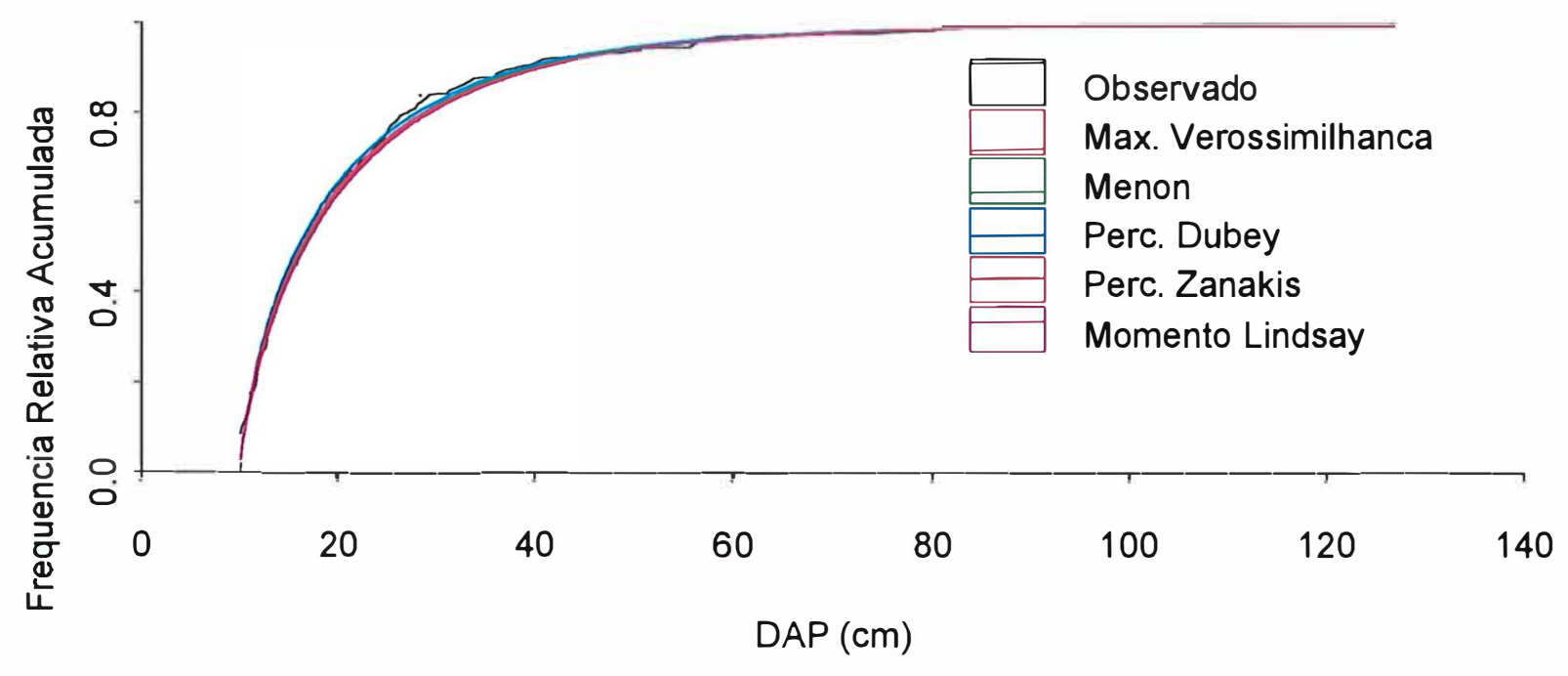

Tratamento 1 medicao 4

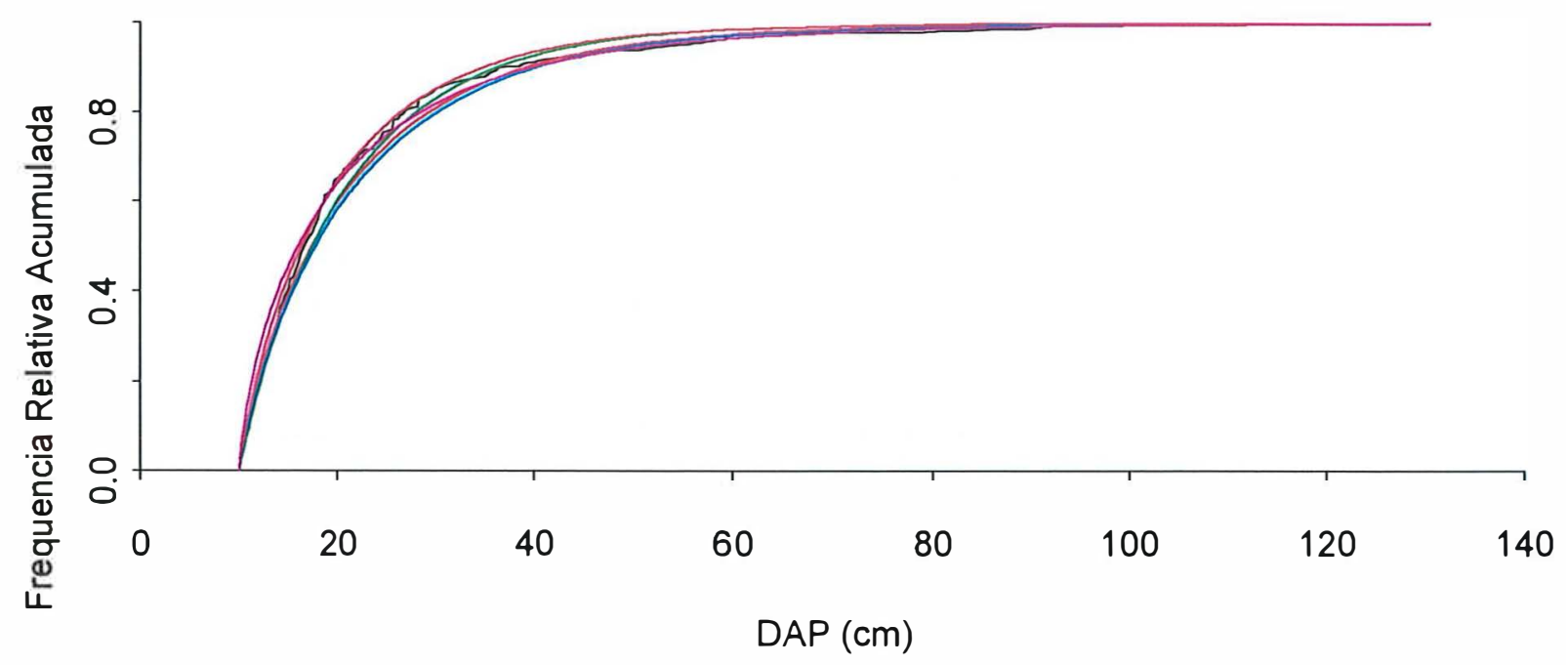

Figura 6 - Freqüências relativas acumuladas dos dados observados e estimados por cinco métodos no tratamento 1 , medições 1 e 4 . 
o

\section{Tratamento 4 medicao 1}

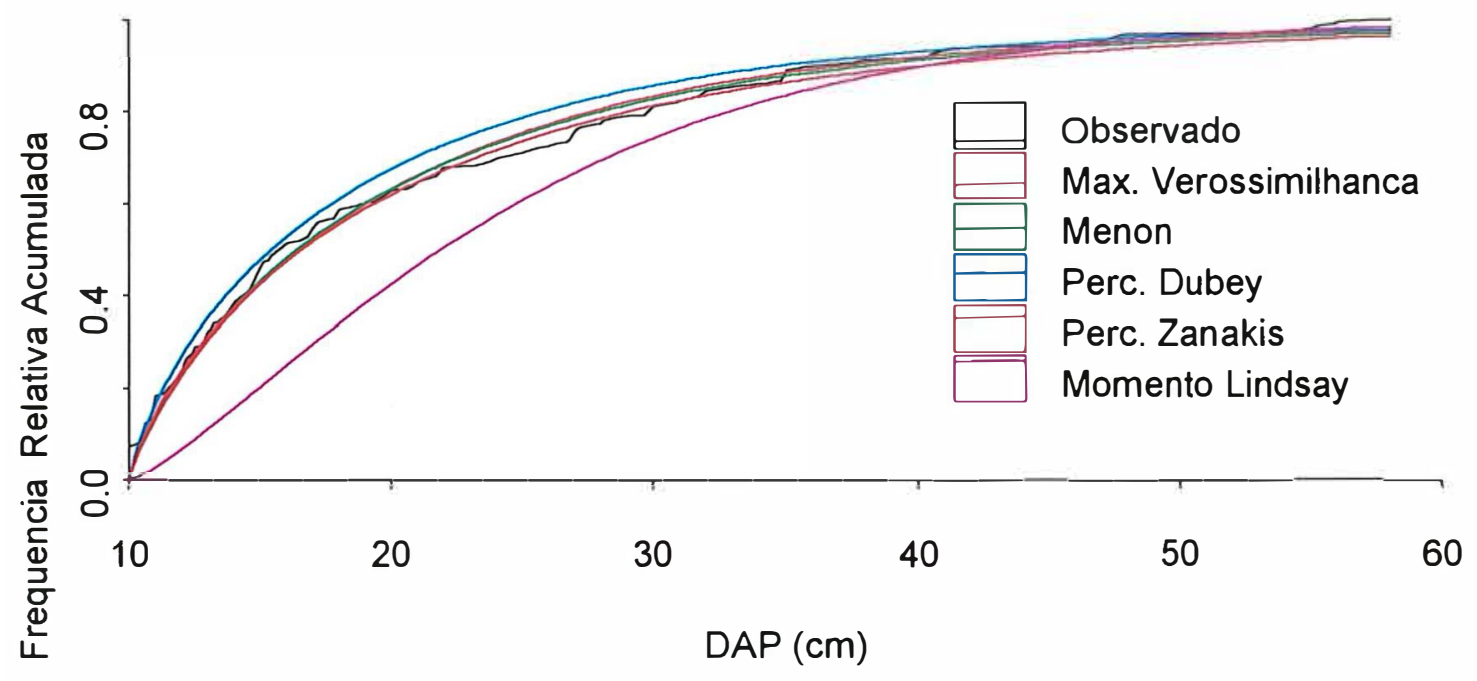

\section{Tratamento 4 medicao 4}



Figura 7 - Freqüências relativas acumuladas dos dados observados e estimados por cinco métodos no tratamento 4 , medições 1 e 4 . 


\section{Tratamento 6 medicao 1}

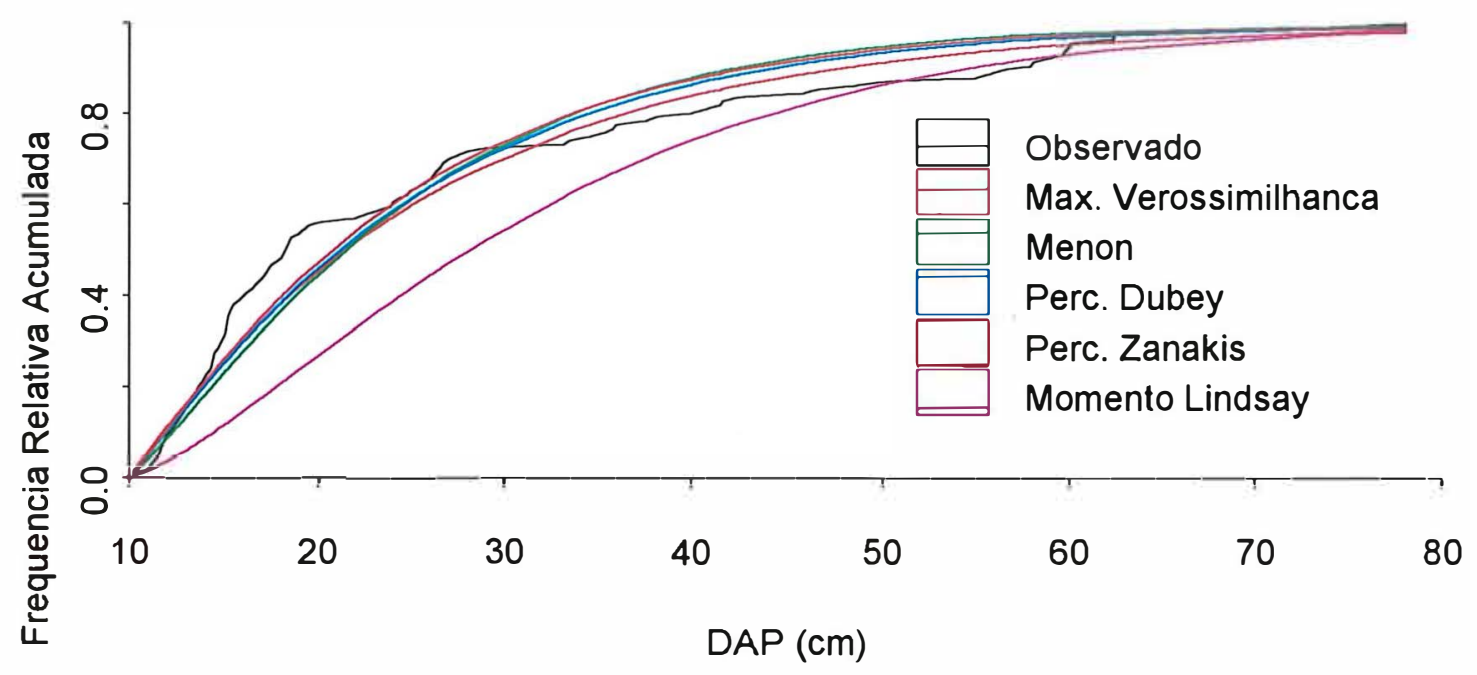

\section{Tratamento 6 medicao 4}



Figura 8 - Freqüências relativas acumuladas dos dados observados e estimados por cinco métodos no tratamento 6 , medições 1 e 4 . 


\section{Tratamento 7 medicao 3}

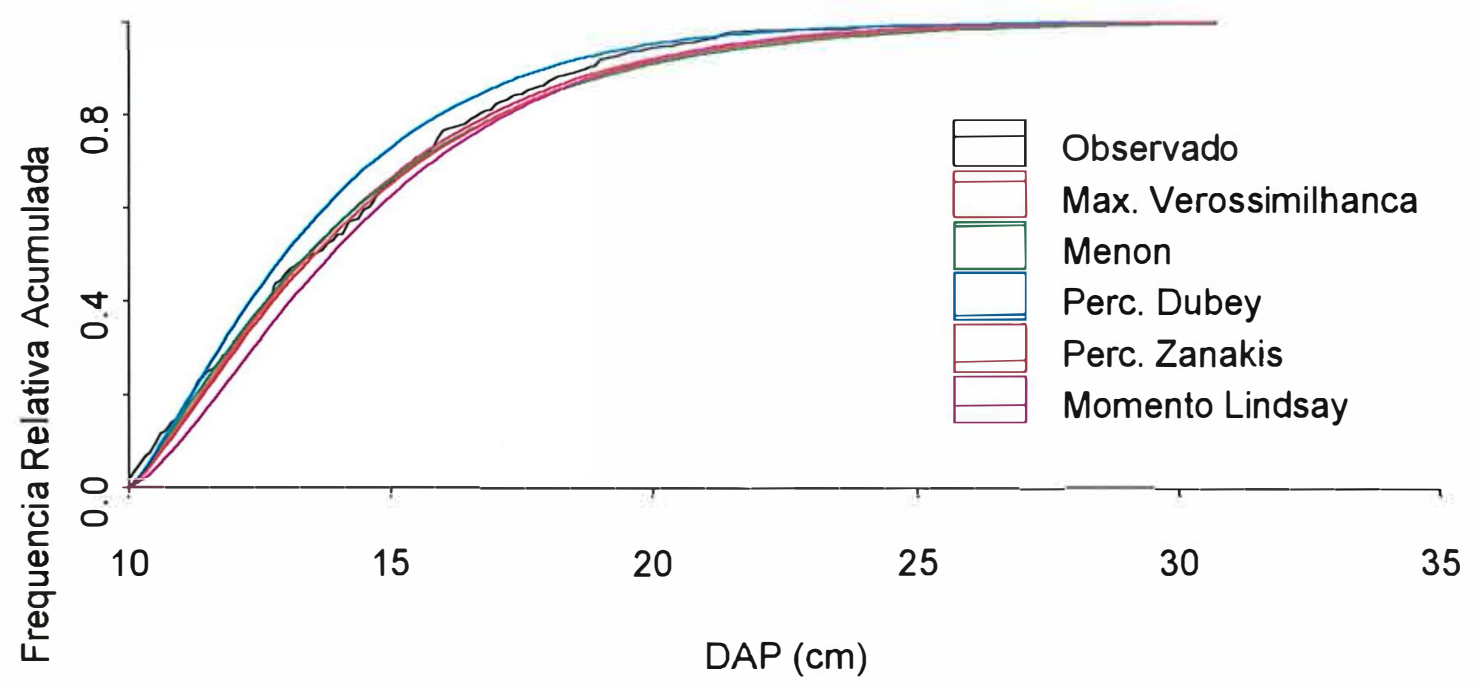

\section{Tratamento 7 medicao 4}



Figura 9 - Freqüências relativas acumuladas dos dados observados e estimados por cinco métodos no tratamento 7 , medições 3 e 4 . 


\section{Tratamento 9 medicao 1}

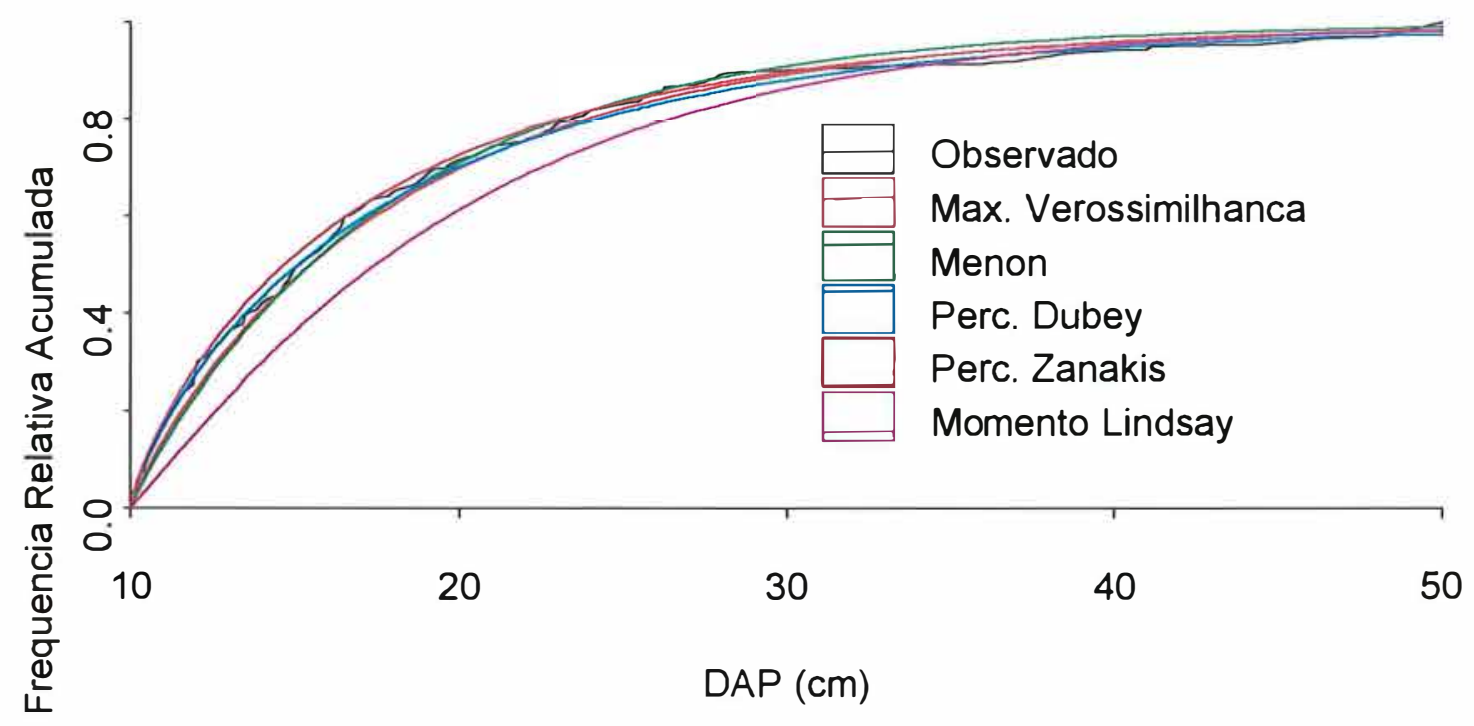

Tratamento 9 medicao 4

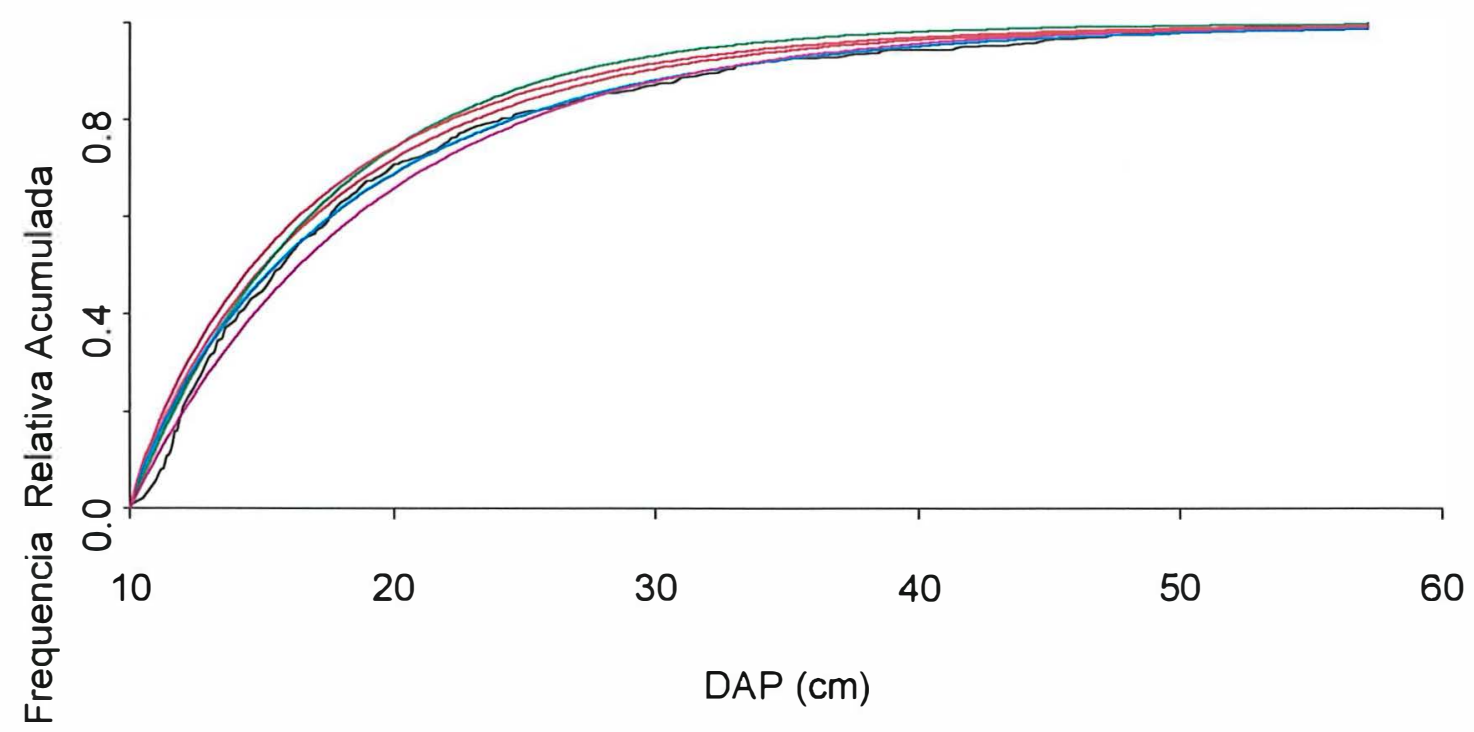

Figura 10 - Freqüências relativas acumuladas dos dados observados e estimados por cinco métodos no tratamento 9 , medições 1 e 4 . 


\subsection{DISCUSSÃO}

A Modelagem de florestas tropicais é complexa pois existe uma grande variação nas espécies presentes e no tamanho das árvores. Imediatamente após o corte seletivo, a distribuição diamétrica da floresta é o resultado da intensidade e tipo do corte seletivo. Com o ingresso de novas árvores e o crescimento das árvores remanescentes, a estrutura diamétrica da floresta tende a retornar ao seu estado original. Os resultados mostraram que tanto o tipo e intensidade do corte seletivo quanto o tempo após a sua aplicação influenciam a qualidade das estimativas dos métodos de ajuste.

O método da Máxima Verossimilhança parece não ter sofrido influência do corte seletivo para estimar o diâmetro médio e o diâmetro médio quadrático, pois obteve erros pequenos. Dubey também não, sendo este o segundo melhor método para estimar estas variáveis.Os métodos de Menon, Zanakis e Lindsay obtiveram, cada, mais de $40 \%$ das observações de DADQ maiores que $1,5 \mathrm{~cm}$. Além disso, os dois primeiros métodos estimaram mal o tratamento l onde se esperava obter uma boa performance. Por estas razões, estes métodos não são apropriáveis para estimar o DG de florestas tropicais que sofreram intervenção.

Para DADG e DADM, o tratamento 7 obteve boas estimativas. É provável que este fato tenha ocorrido pelo crescimento homogêneo do povoamento no período estudado, sendo semelhante a de uma floresta plantada. Já o tratamento 6, salvo Máxima Verossimilhança, os métodos não conseguiram estimar bem o diâmetro médio quadrático e o diâmetro médio. No primeiro caso, os métodos conseguiram estimar os parâmetros $c$ e $b$ de modo a estimar bem DG e DM, ao contrário do segundo. Talvez estes fatos tenham ocorridos pela amplitude das caldas das distribuições que forçou o erro da estimação.

Quanto à distribuição diamétrica por classe de diâmetro, esta foi modificada nos diferentes tratamentos. De acordo com o tratamentos, os métodos de estimação apresentaram performance diferentes. Os métodos de Máxima Verossimilhança e Menon não apresentaram diferença estatística, pelo teste $\mathrm{KS}$ ao nivel de significància de $5 \%$, em nenhum dos casos estudados. Em contraste, o método de Lindsay não obteve sucesso em $80 \%$ dos casos, sendo este método desaconselhável para uso em florestas tropicais. Os dois métodos de percentis apresentaram diferença estatística da distribuição observada em $20 \%$ dos casos. Ainda que os 
métodos que utilizaram percentis não mostraram ser tão eficientes quanto Máxima Verossimilhança e Menon, as estimativas do parâmetros desse método são mais simples de serem estimados.

\subsection{CONCLUSÕES}

Menon, Lindsay e Zanakis não estimaram satisfatoriamente $\hat{\overline{\mathrm{D}}}_{\mathrm{g}}$ e $\hat{\bar{D}}$, sendo estes métodos não aconselháveis para estimarem estas variáveis. Vale ressaltar que Menon não apresentou diferença estatística, no teste KS, para nenhum distribuição diamétrica.

Máxima Verossimilhança mostrou ser o mais eficiente para estimar o $\hat{\bar{D}}_{\mathrm{g}}, \hat{\bar{D}}$ e a distribuição diamétrica, independente das situações estudadas. Esta performance foi seguida por Dubey, ainda que este não tenha sido tão eficiente quanto Máxima Verossimilhança.

As técnicas apropriadas para ajustar os parâmetros da distribuição dependem da eficiência estatística desejável e da capacidade computacional disponíveis (Bailey \& Dell, 1973).

Ratificando a conclusão do trabalho de Bailey \& Dell (1973), nas situações estudadas, recomenda-se o uso de Máxima Verossimilhança quando há disponibilidade computacionais. Se não houver a disponibilidade, recomenda-se o uso do método de Dubey. 


\section{4- AVALIAÇÃO DE DOIS SISTEMAS QUE ESTIMAM A ESTRUTURA DIAMÉTRICA DE UMA FLORESTA TROPICAL SOB DIFERENTES FORMAS DE MANEJO}

\section{RESUMO}

A estrutura diamétrica em florestas permite aferir sobre futuras colheitas e avaliar tratamentos silviculturais aplicados ao povoamento. Além disto, apresenta amplitude dos diâmetros; mostra as classes diamétricas onde ocorrem maiores concentrações de árvores; permite avaliar a regeneração e recrutamento das árvores. Por causa da flexibilidade, a função Weibull tem sido usada para representar a estrutura diamétrica em floresta. O objetivo deste trabalho foi avaliar dois sistemas que modelam os parâmetros da função Weibull, quando ela representa uma floresta tropical que sofreu corte seletivo. O método de predição dos parâmetros usou como variável dependente os parâmetros $c$ e $b$, estimados pelo método de máxima verossimilhança. O método de recuperação usou os percentis 24 e 93 como variáveis dependente, utilizando equações, recuperou os parâmetros c e $b$ da função Weibull. Além das tradicionais variáveis preditoras, como área basal, utilizou-se neste trabalho variáveis que exprimem a diversidade das florestas tropicais. Dentro dos critérios de avaliação, destacaram-se o teste Kolmogorov-Smirnov (KS) ao nível de significância de $5 \%$, diferença dos diâmetros médio observados e estimados e diferença dos diâmetros médios quadráticos observados e estimados. Os resultados mostraram que o sistema de Recuperação dos Parâmetros foi ligeiramente superior ao de Predição. 


\section{SUMMARY}

The diametric structure of forests allows one to estimate for future logging and to evaluate the silvicultural treatments applied to the forest stands. Additionally, it presents the range of diameters; shows the diameter classes where there are higher concentrations of trees; allows the evaluation of tree regeneration and the recruitment. Because its flexibility, the Weibull function has been used to represent the diametric structure on forests. The objective of this study was to evaluate two systems which models the parameters of the Weibull function when it represents a tropical forest that has undergone selective logging. The "parameter prediction" method used as dependent variable the parameters $c$ and $b$, estimated by the maximum likelihood method. The "parameter recovery", method used as dependent variables the percentiles 24 and 93 and, using equations, recovered the parameter $c$ and $b$ of the Weibull function. In this work, besides the traditional predictive variables, like basal area, variables expressing the diversity of tropical forests were also used. Among the evaluation criteria, the most important were the Kolmogorov-Smirnov (KS) test at 5\% significance level, the differences of observed and estimated mean diameters, and the differences of observed and estimated quadratic mean diameters. The results indicate that the parameter recovery method was slightly superior to the parameter prediction method.

\section{1 INTRODUÇÃO}

As florestas dissetâneas têm arranjos espaciais heterogêneas sendo que as árvores variam em idade, tamanho e espécies. Essas florestas sofrem mudanças constantes e utilizam energia solar, nutrientes e água para o crescimento dos tamanhos das árvores sobreviventes (Moser, 1972). As mudanças em florestas ocorrem por: corte ou morte de árvores,

A distribuição diamétrica, como representação da estrutura dos povoamentos, é uma ferramenta usada pelos profissionais florestais decidirem ações e decisões de manejo, ou para avaliar os tratamentos aplicados à floresta (Silva, 1986). Muitas das variáveis que descrevem o povoamento (volume, área basal, diâmetro médio e diâmetro médio quadrático) podem ser expressas como função da distribuição diamétrica .

A função Weibull é uma funções probabilística muito usada em estudos de distribuições diamétricas em florestas (Zarnoch \& Dell, 1985: Silva. 1986 e Lindsay et al., 
1996). Esta função é flexível, cobre formas de distribuições que variam de J-invertido à distribuições em forma de sino (Bailey \& Dell, 1973). A função possui 3 parâmetros; $a$ é chamado do parâmetro de posição, $b$ controla as dimensões que a curva assume (parâmetro de escala) e $c$ controla a forma da curva (parâmetro de forma). Quando $a$ é igual a zero, a função torna-se Weibull dois parâmetros. A função Weibull-3 parâmetros é representado pela seguinte função de densidade probabilística:

$$
f(x)=\frac{c}{b}\left(\frac{x}{b}\right)^{c-1} \exp \left[-\left(\frac{x}{b}\right)^{c}\right] \text { para } \mathrm{x} \geq 0 ; \mathrm{b}>0 \text { e } \mathrm{c}>0 .
$$

Existem dois métodos para estimar os parâmetros da distribuições probabilística quando representa a estrutura diamétrica de uma floresta. No método de predição dos parâmetros, os parâmetros da distribuição são estimados a partir das variáveis do povoamentos (área basal, número de árvores por hectare, diâmetro médio e etc.) que caracterizam a distribuição do povoamento; no método de recuperação dos parâmetros, os percentis da distribuição é que são estimados a partir das variáveis do povoamento e os parâmetros são "recuperados" a partir dos percentis estimados, (Hyink \& Moser, 1983 e Vanclay, 1994).

Rennolls et al. (1985) sugerem a pesquisa que investigue os efeitos dos tratamentos silviculturais na distribuição diamétrica e nos parâmetros da função Weibull. Conjugado aos estudos da predição da estrutura de florestas, deve ser estudado o efeito de corte seletivos em florestas, pois, o conhecimento dos níveis de corte necessários para a resposta do crescimento máximo (Moser, 1972).

O objetivo do trabalho foi testar a eficiência desses dois sistemas que modelam os parâmetros da função Weibull, quando esta estima a estrutura de uma floresta tropical que sofreu vários níveis de intervenção. Na literatura científica florestal, a função Weibull tem sido usada para prognosticar estruturas diamétricas em florestas temperadas e em tropicais. Mas não foram encontrado referências que indiquem qual o melhor sistema de estimar a estrutura diamétrica em povoamentos que sofreu cortes seletivos em florestas tropicais

As perguntas principais que este trabalho se preocupou em responder foram:

1. Utilizando a função Weibull, qual o sistema (predição dos parâmetros ou recuperação dos parâmetros) que melhor estima a distribuição diamétrica de uma floresta tropical que sofreu intervenção? 
2. Quais as variáveis do povoamento que melhor explicam os modelos de predição ou recuperação dos parâmetros ?

\subsection{MATÉRIAS E MÉTODOS}

\subsubsection{Breve histórico do experimento}

Em 1980, a Reserva Florestal de Linhares começou o estudo do comportamento de uma floresta de Mata Atlântica após o tratamento de corte seletivo. O tipo de floresta do estudo é uma mata de tabuleiro ou floresta densa uniforme. Esta vegetação é típica de floresta Atlântica de terra baixa do sul da Bahia ao norte do Espirito Santo, e representa 63,1\% da reserva de Linhares (Batista, 1994). A Reserva abrange uma área de 21.787 ha, o que corresponde a $25 \%$ da cobertura vegetal remanescente atual do estado do Espírito Santo; localiza-se entre os Municípios de Linhares e São Mateus, ao norte do Estado; geograficamente, situa-se entre os paralelos $19^{\circ} 06^{\prime}$ e $19^{\circ} 19^{\prime}$ de latitude sul e os meridianos $39^{\circ} 45^{\prime}$ e $40^{\circ} 19^{\prime}$ de longitude W Gr. O acesso principal se dá pela estrada BR-101 Norte, na altura do Km 122, (Jesus, 1986; Araujo, 1993 e Batista,1994).

O projeto foi instalado em cinco blocos e nove tratamentos. Cada tratamento ocupa uma área de 0,5 ha $(50 \times 100 \mathrm{~m})$ totalizando a área de 4,5 ha para bloco e 22,5 ha para a área total do ensaio. Em 1980, as árvores com DAPs superiores a $10 \mathrm{~cm}$ foram medidas antes e depois da execução dos tratamentos (não houve a medição após o corte e três anos depois nas parcelas que sofreram corte raso).

Os tratamentos aplicados ao povoamento foram:

Tratamento 1- sem interferência.

Tratamento 2- corte de $15 \%$ da área basal. de modo seletivo, removendo as árvores de maiores DAP;

Tratamento 3- corte de 30\% da área basal. de modo seletivo, removendo as árvores de maiores DAP;

Tratamento 4- corte de $45 \%$ da área basal. de modo seletivo, removendo as árvores de maiores DAP: 
Tratamento 5- corte de todas as árvores com DAP menor $10 \mathrm{~cm}$ e maior de $80 \mathrm{~cm}$ seguindo o corte de $15 \%$ das remanescentes em área basal, de modo seletivo, removendo as maiores árvores residuais;

Tratamento 6- corte de todas as árvores com DAP menor $10 \mathrm{~cm}$ e maior de $80 \mathrm{~cm}$ seguindo o corte de $30 \%$ das remanescente em área basal, de modo seletivo, removendo as maiores árvores residuais;

Tratamento 7- corte raso;

Tratamento 8- corte de todas as árvores com DAP $\geq 80 \mathrm{~cm}$ seguindo o corte de $25 \%$ das remanescente em área basal, de modo seletivo, removendo as maiores árvores residuais;

Tratamento 9- corte de todas as árvores com DAP $\geq 50 \mathrm{~cm}$ seguindo o corte de $25 \%$ das remanescente em área basal, de modo seletivo, removendo as maiores árvores residuais.

\subsubsection{Aspectos fisiogeográficos:}

O relevo da reserva se caracteriza por uma seqüência de colinas tabulares, com altitude variando entre 28 e $65 \mathrm{~m}$, entre cortados por vales amplos e rasos. O substrato geológico é composto principalmente por sedimentos tecernários e quaternários e profundos (de 2 a $4 \mathrm{~m}$ ). O solo são podizolicos, de textura arenosa e baixa fertilidade (Jesus, 1986 e Batista, 1994).

\subsubsection{Aspectos climáticos:}

O clima é considerado "Awi" na classificação de Köppen que significa quente e úmido com verão úmido e inverno seco. A amplitude de temperatura anual varia de mínima $8,3^{\circ} \mathrm{C}$ e máxima de $39,8^{\circ} \mathrm{C}$, e temperatura média é de $23^{\circ} \mathrm{C}$. A pluviosidade varia de 817 a 1639 $\mathrm{mm}$, sendo a média $1230 \mathrm{~mm}$. A umidade relativa permanece alta durante todo o ano, entre $81 \%$ a $85,5 \%$ com média de 83.5 (Batista, 1994). 


\subsubsection{Análises e desenvolvimento dos modelos}

As análises do trabalho foram baseadas nas medições da floresta feitas após a aplicação dos tratamentos em 1980, e nas posteriormente cinco remedições feitas até 1995. O número total de observações foi de 260.

Para o estudo das estimativas da função Weibull, utilizou-se dois sistemas de estimação dos parâmetros: predição dos parâmetros e recuperação dos parâmetros. No sistema de predição dos parâmetros, os parâmetros da função Weibull foram estimados pelo método de máxima verossimilhança, (eq. 7 e 8), desenvolvido por (Cohen, 1965). O sistema de recuperação dos parâmetros consistiu em utilizar os métodos dos percentis (Dubey, 1967). Para este estudo, os estimadores dos parâmetros da função Weibull foram:

$$
\begin{aligned}
& \hat{c}=\frac{\ln \left(-\ln \left(1-p_{1}\right)\right)-\ln \left(-\ln \left(1-p_{2}\right)\right)}{\ln \left(D A P_{p 1}\right)-\ln \left(D A P_{p 2}\right)} \\
& \hat{b}=\left[\frac{p_{1}}{-\ln \left(1-p_{1}\right) \frac{1}{c}}\right]
\end{aligned}
$$

onde: $p_{1}$ e $p_{2}$ são probabilidades $\left(p_{1}=0,24\right.$ e $\left.p_{2}=0.93\right)$

$\operatorname{DAP}_{\mathrm{p} 1}$ e $\mathrm{DAP}_{\mathrm{p} 2}$ são os percentis da distribuição diamétrica e Ln indica logaritmo neperiano

Para a construção dos modelos, 260 parcelas forma utilizadas nas regressões lineares. O sistema de predição dos parâmetros constituiu em modelar os parâmetros $c$ e $b$ como variável dependente; o sistema de recuperação dos parâmetros modelou os percentis 24 e 93 como variável dependente.

- $\mathrm{N}$ - densidade do povoamentos (arv/ha);

- Nc- número de árvores cortadas na ocasião do corte seletivo (arv/ ha);

- G-área basal do povoamento ( $\left.\mathrm{m}^{2} / \mathrm{ha}\right)$;

- Gc- área basal cortada na ocasião do corte seletivo ( $\left.\mathrm{m}^{2} / \mathrm{ha}\right)$; 
- Gr- área basal remanescente imediatamente após a aplicação do corte seletivo ( $\mathrm{m}^{2} / \mathrm{ha}$ ) ou seis anos após o corte raso (tratamento 7);

- S- riqueza de espécies do povoamento, definido como a contagem das espécies numa área (Magurran, 1988);

- Sr- riqueza remanescente imediatamente após a aplicação do corte seletivo ( $\mathrm{m}^{2} / \mathrm{ha}$ ) ou seis anos após o corte raso (tratamento 7);

- Sn-riqueza por densidade do povoamento;

- Snr- riqueza remanescente por densidade remanescente após a aplicação do corte seletivo $\left(\mathrm{m}^{2} / \mathrm{ha}\right.$ ) ou seis anos após o corte raso (tratamento 7$)$ );

- H- índice de diversidade de Shanon (Magurran, 1988) do povoamento;

- T- tempo após aplicação do corte seletivo (anos).

Para desenvolver os modelos utilizou-se a sugestão de Zar (1996); a variável independente foi função de todas as variáveis preditoras, retirando-se as que o coeficiente parcial não tinha diferença significativa. Mas ocorreu casos que a equação final não era satisfatória por apresentar heterocedasticidade. Neste casos foram testados outras variáveis por tentativa e erro.

\subsubsection{Avaliação dos modelos}

Os modelos estudados foram avaliados por: coeficiente de determinação $\left(R^{2}\right)$; gráficos de variância; teste de Kolmogorov-Smirnov (KS) de qualidade de ajuste ao nível de significância de 5\% para amostras grandes (Sokal \& Rohlf, 1981); diferença dos diâmetros médio quadráticos observados e estimados (DDG); diferença dos diâmetros médios observados e estimados (DDM).

O diâmetro médio (Lindsay et al.. 1996) e diâmetro médio quadrático (Batista, (1989), citando Burk \& Neubery) foram obtidos a partir dos parâmetros estimados utilizando as relações::

$$
\hat{\bar{D}}=\hat{a}+\hat{b} \Gamma_{1}
$$




$$
\begin{aligned}
& \hat{\overline{\mathrm{D}}}_{\mathrm{g}}=\sqrt{\hat{\mathrm{a}}^{2}+2 \hat{\mathrm{a}} \hat{\mathrm{b}} \Gamma_{1}+\hat{\mathrm{b}}^{2} \Gamma_{2}} \\
& \text { onde: } \Gamma_{k}=\Gamma\left(1+\frac{1}{c}\right) \quad \mathrm{e} \\
& \qquad a, b \text { e } c \text { são parâmetros da função Weibull. }
\end{aligned}
$$

\subsubsection{Multicolinariedade}

A correlação que existe entre variáveis independente é conhecida como multicoliniariedade. Se as variáveis preditoras são correlacionadas, não se pode assumir que os coeficientes das regressões parciais associados à variável preditoras refletem a dependência da variável dependente (Zar, 1996). O fator de inflação da variância (FIV) é um auxiliar da regressão que examina correlação entre variáveis preditoras (Sokal 1998). Se FIV é igual a 1, não existe colineariedade; se o valor é maior que 5 , indica que a colineariedade pode prejudicar a precisão das equações. (Liu et al., 1989).

$$
C_{i i} \sum X_{i}^{2}
$$

onde: $C_{i i}$ elementos da diagonal principal da matriz inversa do delineamento do modelo de regressão $\left(\left[\mathrm{X}^{\prime} \mathrm{X}\right]\right)^{-1} \mathrm{e}$ $X$ é a variável preditora da matriz.

\subsection{RESULTADOS E DISCUSSÃO}

\subsubsection{Modelos do sistema de Predição dos Parâmetros}

As equações que utilizaram o método de Predição dos Parâmetros e os respectivos desempenhos dos modelos estão descritas na tabela 3. Este método apresentou os coeficientes de determinação superior ao citado por Bailey et al. (1981). Segundo estes autores, pelo menos um dos parâmetros modelados possuiriam coeficiente de determinação inferior a 10. 


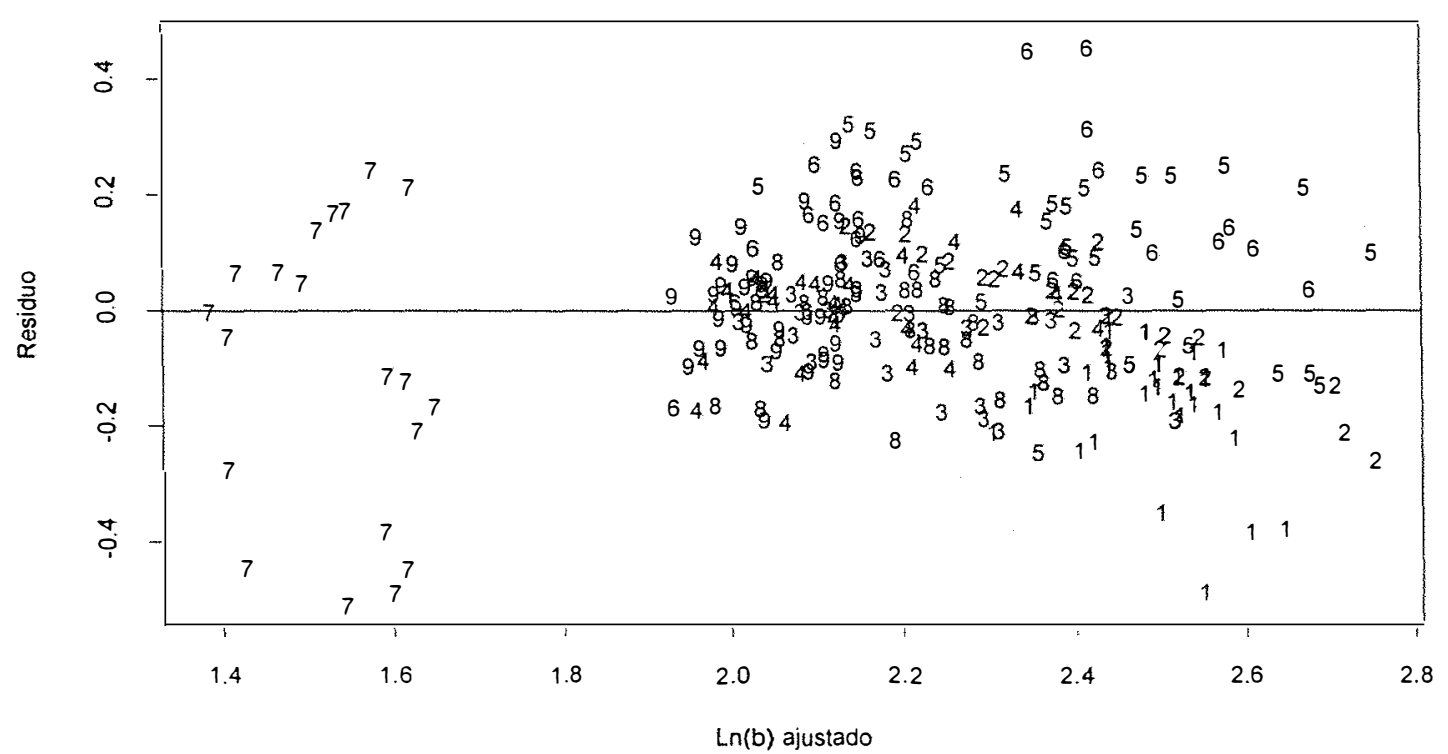

Figura 11- Distribuição dos resíduos das estimativas de $\operatorname{Ln}(b)$, identificando o tratamento aplicado à floresta.

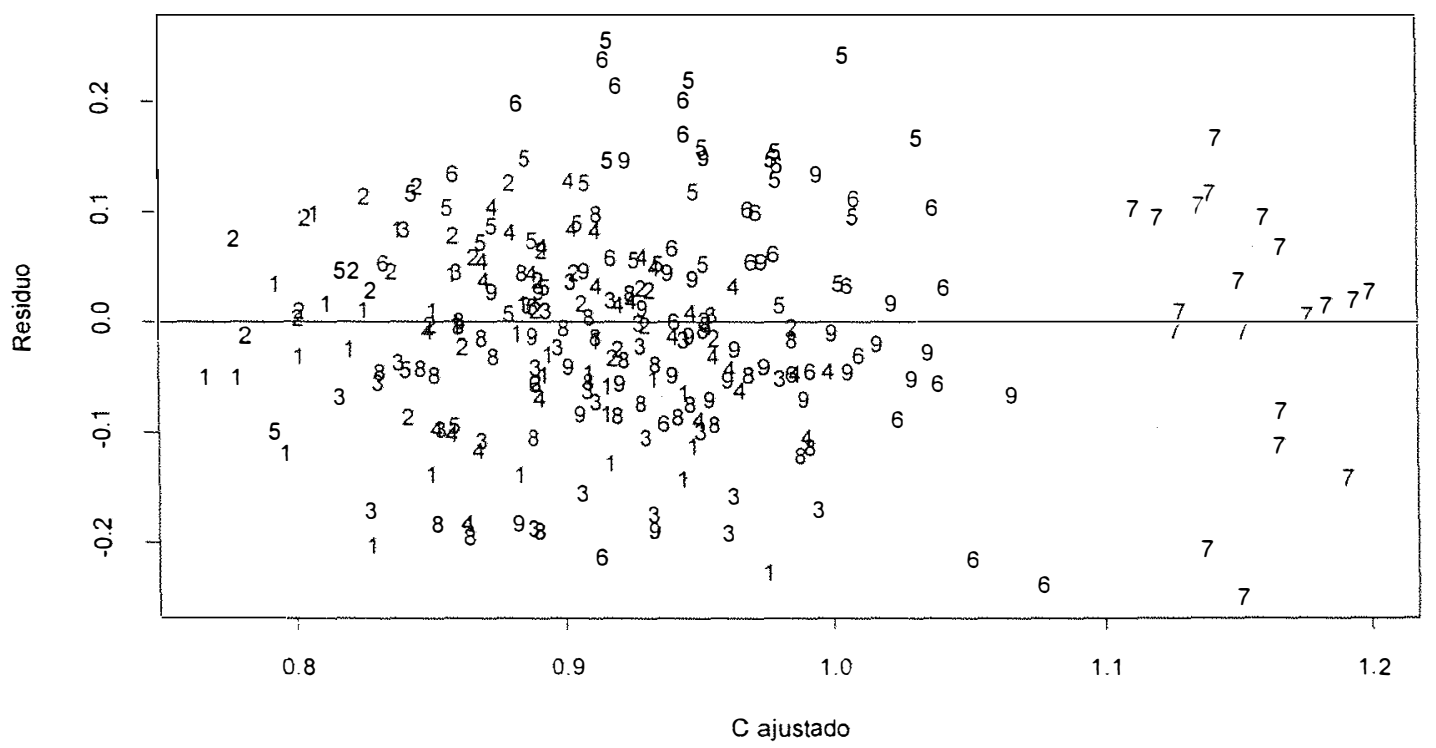

Figura 12- Distribuição dos resíduos das estimativas do parâmetro de forma $(c)$, identificando o tratamento aplicado à floresta. 


\subsubsection{Modelos do sistema de Recuperação dos Parâmetros}

Os modelos que utilizaram o método de Recuperação dos Parâmetros estão descritos na tabela 4. Todos os modelos descritos apresentaram o valor de FIV inferior a 5 e as distribuições dos resíduos apresentavam homocedasticidade.

Nos modelos do percentil 93, com freqüência, os coeficientes parciais da variável tempo não apresentava diferença significativa (modelos 6, 7, 10,11 e 15, tabela 4). Dos modelos que apresentaram o coeficiente parcial significativo, o 8 e 9 apresentaram o erro com valor alto (17), sendo esta a razão de desclassificá-los.

Por apresentarem maiores coeficiente de determinação e menores erros, foram selecionados o modelo 3 para o percentil $24\left(\mathrm{p}_{24}\right)$ e o 12 , para o percentil $93\left(\mathrm{p}_{93}\right)$. O modelo 3 $\left(\mathrm{p}_{24}\right)$ teve como amplitude dos resíduos valores entre $-1,7 \mathrm{a}+1,8 \mathrm{~cm}$. Das observações feitas, $50,76 \%$ (132) foram negativas e 49,23\% (128) positivas. A amplitude dos resíduos para o modelo $12\left(\mathrm{p}_{93}\right)$ variou entre $-9,7$ a $+8,7 \mathrm{~cm}$. A distribuição dos resíduos 12 foi composta por: 48,07\% (125) casos negativos e 51,92\% (135) positivos. Os dois modelos escolhidos não apresentaram viés nas estimativas. As figuras 13 e 14 mostram a distribuição dos erros dos percentis 24 e 93. 
Tabela 4- Modelos para estimativas dos percentis 24 e 93, cujas variáveis independentes são atributos do povoamento.

\begin{tabular}{clcc}
\hline $\mathrm{N}^{\circ}$ & Modelo & $\mathrm{R}^{2}$ & $\mathrm{~S}_{\mathrm{y}}$ \\
\hline 1 & $\mathrm{P}_{24}=13,9375-0.0054 \mathrm{~N}+0.0681 \mathrm{G}-0.0018 \mathrm{Nc}-0,0066 \mathrm{~S}^{*}+0.0698 \mathrm{~T}$ & 0,46 & 0,71 \\
2 & $\mathrm{P}_{24}=13.0753-0.0058 \mathrm{~N}+0.0842 \mathrm{G}+0.0624 \mathrm{~T}$ & 0,44 & 0,71 \\
3 & $\mathrm{P}_{24}=11,08198+0.0773 \mathrm{G}-0.03 \mathrm{~S}+0,0711 \mathrm{~T}+22,9563 \mathrm{Sn}-12.3533 \mathrm{Snr}$ & 0,53 & 0,65 \\
4 & $\mathrm{P}_{24} /(\mathrm{Gc}+0,1)=(13,5611-0.0053 \mathrm{~N}+0.0880 \mathrm{G}-0,0018 \mathrm{Gc}-0.0074 \mathrm{~S})^{*} 1 /(\mathrm{Gc}+0.1)$ & 0,57 & 2,49 \\
& & & \\
5 & $\mathrm{P}_{24} /(\mathrm{Gc}+0,1)=(12,5954-0,0058 \mathrm{~N}+0,1070 \mathrm{G}+0,0657 \mathrm{~T} /(\mathrm{Gc}+0,1)$ & 0,55 & 2,53 \\
6 & $\mathrm{P}_{93}=8,7957+0.9092 \mathrm{G}+0,0186 \mathrm{Nc}-0,0721 \mathrm{~T}^{*}+194,0392 \mathrm{Sn}-139.8551 \mathrm{Snr}$ & 0,74 & 4,68 \\
7 & $\mathrm{P}_{93}=0,9857 \mathrm{G}+0,0267 \mathrm{~N} \mathrm{RET}-0,0752 \mathrm{~T}^{*}+199,3861 \mathrm{Sn}-111.8398 \mathrm{Snr}$ & 0,98 & 4,72 \\
8 & $\mathrm{P}_{93} /(\mathrm{Gc}+0,1)=\left(9.3564+1.1550 \mathrm{G}+0.0189 \mathrm{Nc}-0,2657 \mathrm{~T}+163.4002 \mathrm{Sn}-133,3413 \mathrm{Snr}_{\mathrm{i}}\right)^{*} 1 /$ & 0,81 & 17,26 \\
& $(\mathrm{Gc}+0.1)$ & & \\
9 & $\mathrm{P}_{93} /\left(\mathrm{G}_{\mathrm{c}}+0.1\right)=(1.2310 \mathrm{G}+0.0267 \mathrm{Nc}-0.2825 \mathrm{~T}+164.6949 \mathrm{Sn}-96.8270 \mathrm{Snr})^{*} 1 /(\mathrm{Gc}+0.1)$ & 0,98 & 17,38 \\
& & & \\
10 & $\mathrm{P}_{93}=-7,8874-0.0628 \mathrm{~N}+26.1544 \mathrm{LOG}(\mathrm{G})+0.0098(\mathrm{Nc})-0.0247 \mathrm{~T}$ & 0,88 & 3,12 \\
11 & $\mathrm{P}_{93}=-47,8975-0,0570 \mathrm{~N}+1.0061 \mathrm{G}-0.0147(\mathrm{Nc})-0.0656 \mathrm{~T} *$ & 0,80 & 4,05 \\
12 & $\mathrm{P}_{93}=15,0169+1,030828 \mathrm{G}-0,2682048 \mathrm{~S}+0,08887846 \mathrm{~T}+220,3231 \mathrm{Sn}-73,92774 \mathrm{Snr}$ & 0,88 & 3,19 \\
& & & \\
13 & $\mathrm{P}_{93}=8,676209+1,067336 \mathrm{G}-0,162747 \mathrm{~S}-0,3529386 \mathrm{~T}+133,2804 \mathrm{Snr}$ & 0,60 & 5,08 \\
14 & $\mathrm{P}_{93}=-27,25922+22,62139 \log (\mathrm{G})-0,2257 \mathrm{~S}-0,3477 \mathrm{~T}+117,0229 \mathrm{Snr}$ & 0,67 & 5,27 \\
15 & $\mathrm{P}_{93}=22,3239+0,7218 \mathrm{G}-0,0250 \mathrm{~T}^{*}+170,7714 \mathrm{Sh}-158,931 \mathrm{Snr}$ & 0,72 & 4,85 \\
\hline
\end{tabular}

* indica que a estimativa da variável não apresenta diferença significativa.

** $\mathrm{N}$ é - densidade do povoamentos: Nc é número de árvores cortadas na ocasião do corte seletivo (arv/ ha):G é área basal do povoamento ( $\left.\mathrm{m}^{2} / \mathrm{ha}\right)$; Gc é área basal cortada na ocasião do corte seletivo ( $\left.\mathrm{m}^{2} / \mathrm{ha}\right)$ : Gr é área basal remanescente imediatamente após a aplicação do corte seletivo $\left(\mathrm{m}^{2} /\right.$ ha) ou seis anos após o corte raso (tratamento 7); S é riqueza de espécies do povoamento, definido como a contagem das espécies numa área (Magurran, 1988); Sr é riqueza remanescente imediatamente após a aplicação do corte seletivo $\left(\mathrm{m}^{2} / \mathrm{ha}\right)$ ou seis anos após o corte raso (tratamento 7); Sn é riqueza por densidade do povoamento: Snr é riqueza remanescente por densidade remanescente após a aplicação do corte seletivo ( $\mathrm{m}^{2} / \mathrm{ha}$ ) ou seis anos após o corte raso (tratamento 7 ); $\mathrm{H}$ - índice de diversidade de Shanon e T é o tempo após a aplicação do corte seletivo. 


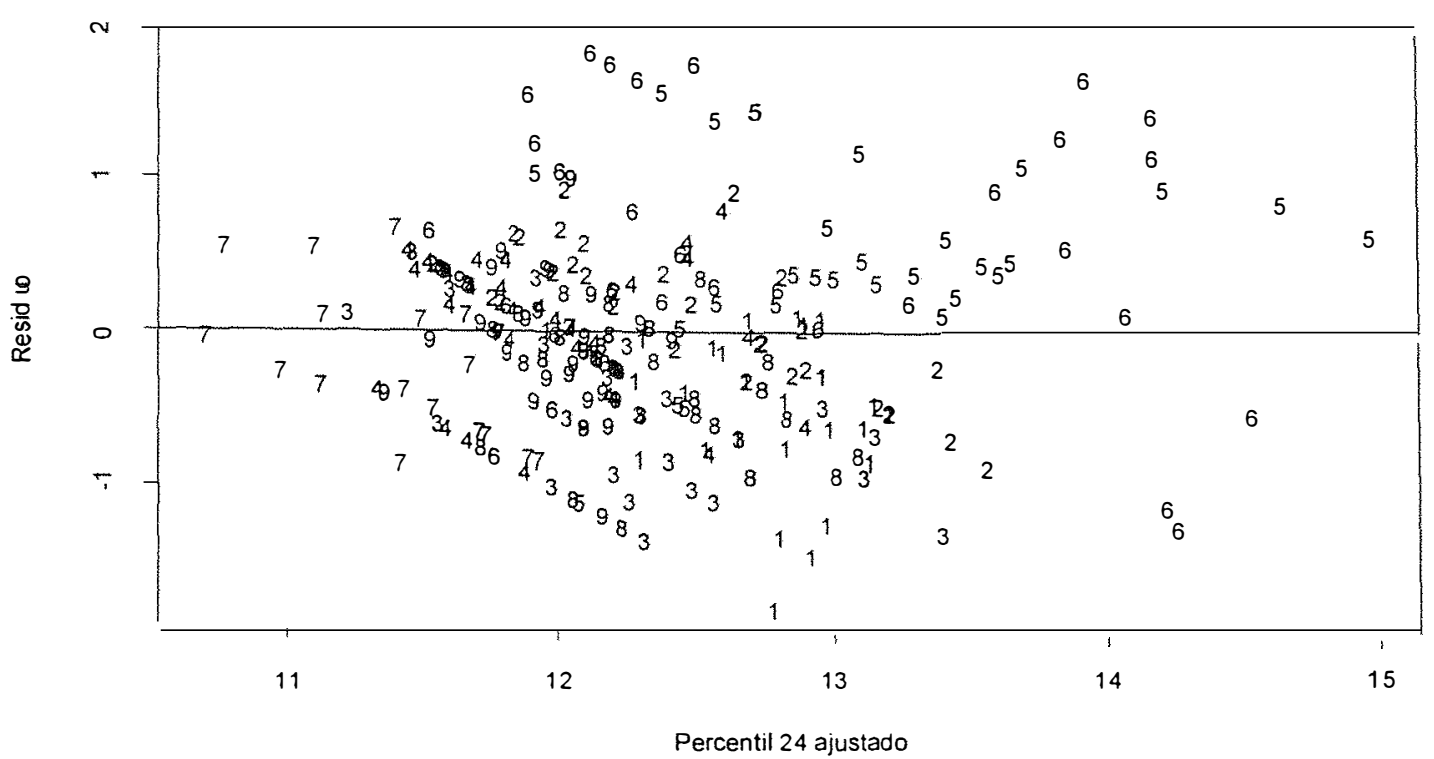

Figura 13- Distribuição dos resíduos das estimativas do percentil 24, identificando o tratamento aplicado à floresta.

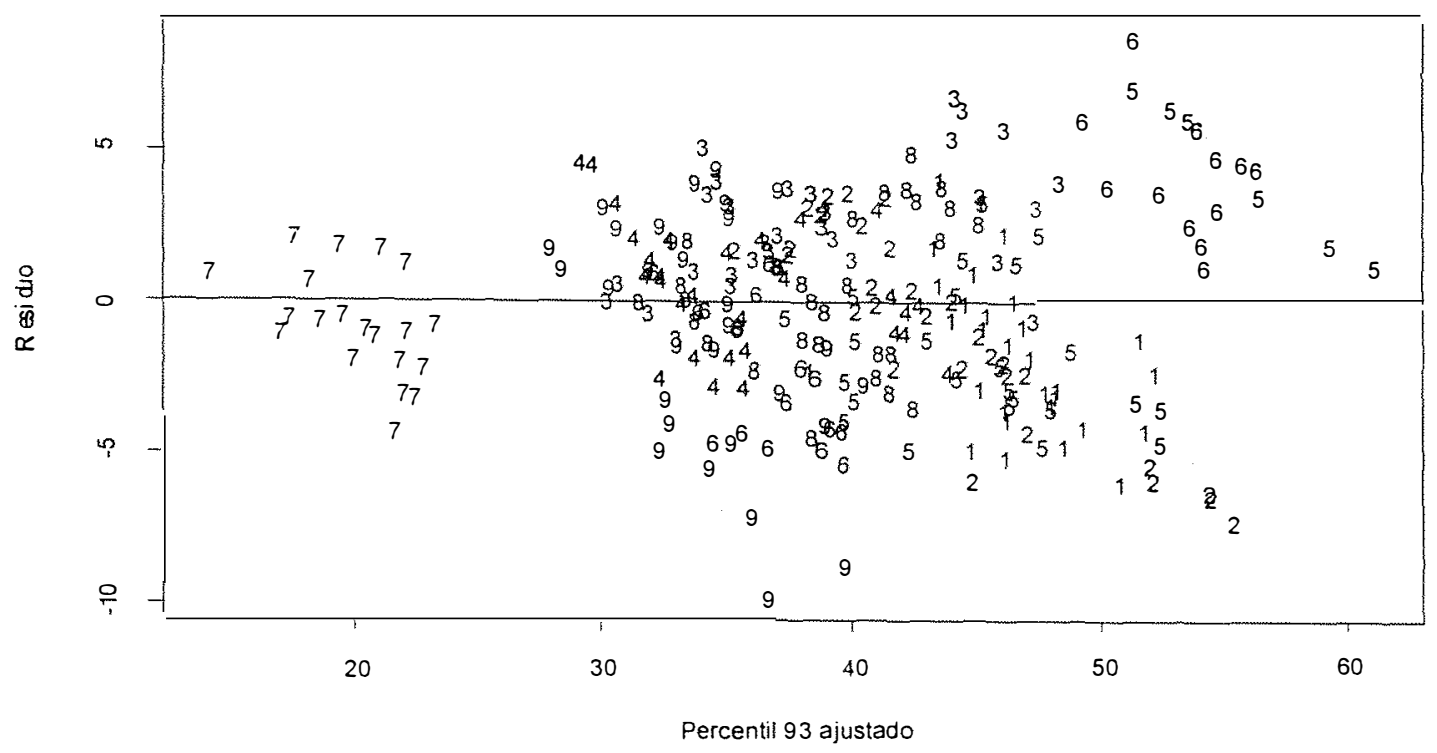

Figura 14- Distribuição dos resíduos das estimativas do percentil 93, identificando o tratamento aplicado à floresta. 


\subsubsection{Qualidade dos modelos desenvolvidos}

Das 260 observações, Predição dos Parâmetros apresentou diferença significativa em 26,15\% (68) das parcelas, enquanto Recuperação dos Parâmetros obteve em 21,92\% (57). As diferenças significativas entre distribuições observada e estimada refletem a variação na forma e localização que não é explicado pelo modelo.

Predição dos Parâmetros apresentou, ao menos numa parcela de cada tratamento, diferença significativa pelo teste KS. Os tratamentos que apresentaram diferença significativa em mais de dez parcelas foram o 1, 5 e 7; o tratamento 1 foi o que mais apresentou parcelas com diferença (20). Os três tratamentos somam 66\% (45) das parcelas que obtiveram diferença.

Recuperação dos Parâmetros obteve nos tratamentos 5, 6 e 8 mais de dez parcelas com diferença significativa; o tratamento 5 foi o que apresentou mais diferença significativa (15). A soma dos três representa $66 \%$ (38) do total. Os tratamentos 3 e 4 não apresentaram nenhuma diferença significativa.

O método de Recuperação teve a melhor performance para estimar o diâmetros médios quadráticos. Para este método, 72,69\% (189) dos DDG localizavam-se no intervalo de \pm $1 \mathrm{~cm}$ contra 49,23\% (128) do método de Predição dos Parâmetros. O intervalo de $\pm 2 \mathrm{~cm}$ continha 91,53\% (238) das observações de DDG para Recuperação, contra 80,76\% (210) do método de Predição, (tabela 5).

A amplitude de DDG para Predição dos Parâmetros foi de $-3,20$ a 7,57 cm. Os desvios foram composto com 35\% (91) das observações negativas e 65\% (169) positivas. DDG variou entre $-4,49$ a 1,48 cm no sistema de Recuperação dos Parâmetros; os desvios foram composto por $72,30 \%$ (188) observações negativas e 27,79\% (72) positivas. O sistema de Recuperação tendeu a subestimar DG, enquanto Recuperação tendeu a superestimar DG.

Tabela 5- Distribuições de DDG dos métodos de Predição e Recuperação dos parâmetros.

\begin{tabular}{lccc}
\hline Método & DDG $(\mathrm{cm})$ & $\mathrm{N}$ & \% de casos \\
\hline Predição & $-1,0 \mathrm{a}+1,0$ & 128 & 49,23 \\
& $-2,0 \mathrm{a}+2,0$ & 210 & 80,76 \\
& $-3,0 \mathrm{a}+3,0$ & 252 & 96,92 \\
Recuperação & $-1,0 \mathrm{a}+1,0$ & 189 & 72,69
\end{tabular}




$\begin{array}{lll}-2,0 \mathrm{a}+2,0 & 238 & 91,53 \\ -3,0 \mathrm{a}+3,0 & 253 & 97,30\end{array}$

O método de Recuperação foi ligeiramente superior ao método de Predição para estimar os diâmetros médios. Recuperação dos Parâmetros apresentou 76,53\% (199) dos DDM entre $\pm 1 \mathrm{~cm}$, contra 63,84\% (166) do método de Predição. O intervalo de $\pm 2 \mathrm{~cm}$ continha 96,15\% (250) das observações de DDM para Recuperação, contra 90\% (234) do método de Predição, (tabela 6).

A amplitude de DDM para Predição dos Parâmetros foi de $-3,13$ a $5,87 \mathrm{~cm}$; a distribuição dos desvios fó composta por 45,38\% (118) casos negativos e 54,62\% (142) positivos. A amplitude de DDM para Recuperação dos parâmetros foi de $-3,05$ a $1,03 \mathrm{~cm}$; a distribuição dos desvios foi composta por 74,61\% (194) casos negativos e 25,38\% (66) positivos. O sistema de Predição não apresentou viés enquanto Recuperação tendeu à superestimar DM.

Tabela 6- Distribuições de DDM dos métodos de Predição e Recuperação dos parâmetros.

\begin{tabular}{lccc}
\hline Método & DDM $(\mathrm{cm})$ & $\mathrm{N}$ & \% de casos \\
\hline Predição & $-1,0 \mathrm{a}+1,0$ & 166 & 63,84 \\
& $-2,0 \mathrm{a}+2,0$ & 234 & 90,00 \\
& $-3,0 \mathrm{a}+3.0$ & 254 & 97,69 \\
Recuperação & $-1,0 \mathrm{a}+1.0$ & 199 & 76,53 \\
& $-2,0 \mathrm{a}+2,0$ & 250 & 96,15 \\
& $-3,0 \mathrm{a}+3,0$ & 251 & 99,51 \\
\hline
\end{tabular}

\subsubsection{Relação entre os tratamento e os sistemas de Predição dos Parâmetros e Recuperação dos Parâmetros}

Cortes seletivos tem como propósito aumentar o crescimento do povoamento remanescente e/ou melhor a forma das árvores (Kuru. 1992). Estudo anterior na Reserva Florestal de Linhares mostrou que, conforme o tratamento, a intervenção pode provocar mudanças na estrutura diamétrica. área basal, crescimento e mortalidade das árvores. 
Tratamentos que envolveram corte de limpeza (eliminação de árvores inferiores a $10 \mathrm{~cm}$ de DAP) apresentaram crescimentos inferiores e mortalidade superior aos que não envolveram; estes tratamentos também apresentaram deficiência no ingresso da regeneração; os tratamentos que foram submetidos a alta intensidade de corte, apresentaram menor recuperação em relação aos que não sofreram; o tratamento que retirou $15 \%$ da área basal, a partir das árvores de maior diâmetro, apresentou a mais rápida recuperação, não sofreu a invasão de espécies indesejáveis e já permitia nova colheita dez anos após a intervenção, (Jesus et al., 1992).

Estas mudanças ocorridas no povoamento são verificadas pela dinâmica dos valores estimados do sistemas de predição dos parâmetros e recuperação dos parâmetro. De acordo com os tratamentos, ocorreram os agrupamentos dos valores dos paràmetros $(b$ e $c)$ e dos percentis $\left(\mathrm{p}_{24}\right.$ e $\mathrm{p}_{93}$ ), sendo este fato mostrado nos gráficos da distribuição dos resíduos (fíguras $11,12,13$ e 14).

O agrupamento do tratamento 7 é o mais explicito. Neste tratamento, após o corte, o povoamento apresentou menor dispersão (figura 11). Em relação ao parâmetro $c$, ele variou entre 1 e 1,3 (figura 12). Para esta situação, a distribuição tem a forma assimétrica a esquerda (Vanclay, 1994), característica de povoamento em crescimento.

Os tratamentos 5 e 6 agrupam-se também. Eles tiveram como característica principal o corte de limpeza. Como as últimas observações corresponderam aos últimos anos de inventário, observou-se que o corte seletivo aumentou o percentil 24 e 93 destes tratamentos. O motivo do aumento do percentil 24 pode estar relacionado ao baixo recrutamento das árvores abaixo de $10 \mathrm{~cm}$, simultaneamente, houve o crescimento das árvores menores. O corte seletivo também pode ter proporcionado mudança ambientais (espaço físico, competição, disponibilidade de água e nutrientes) que resultou no deslocamento do percentil 93 (figura 14), visto que as últimas observações correspondem às ultimas remedições.

Como verificado acima, os dois sistemas são capazes de verificar as mudanças ocorridas na floresta. Os valores dos percentis e dos paràmetros da função Weibull, em cada momento do estudo, podem ser relacionados com distribuições probabilísticas. Estas distribuições refletem os tratamentos aplicados, permitindo aferir sobre os impactos que os tratamentos exerceram sobre os povoamentos: 


\subsection{CONCLUSÕES}

As estimativas do sistema de predição dos parâmetros obteve o valor do coeficiente de determinação superior ao citado por Bailey et al. (1981). Uma novidade inseridas nas equações de regressão foi a inclusão de variáveis que expressão a diversidade de espécies.

As variáveis preditoras que melhores explicaram os dois sistemas foram: densidade $(\mathrm{N})$, número de árvores cortadas no corte seletivo $(\mathrm{Nc})$, área basal por hectare $(\mathrm{G})$, área basal cortada (Gc), tempo (T), área basal remanescente imediatamente após o corte seletivo (Gr), número de espécie por árvore do povoamento ou seis anos após o corte raso ( $\mathrm{Sn}$ ) e número de espécie por árvore remanescente após a aplicação do corte seletivo ou seis anos após o corte raso (Snr).

Os dois sistemas produziram boas estimativas do diâmetro médio e do diâmetro quadrático médio. A qualidade do ajuste do diâmetro médio quadrático é especialmente importante, pois, a área basal é função do diâmetro quadrático médio e da densidade do povoamento.

Ao estimar a distribuição diamétrica, o sistema de Recuperação dos Parâmetros foi um pouco superior ao de Predição, pois apresentou menor valor do teste KS e a amplitude de DDM e DDG foi menor. Segundo Bailey et al. (1981), a provável razão da performance do sistema de Predição dos Parâmetros é que diferentes conjuntos de parâmetros geram distribuições similares. Esta variação é introduzida pelo processo de ajuste. As estatísticas computadas diretamente dos dados, como os percentis, podem ser mais previsíveis do que as computadas por processo de ajuste.

Utilizando a função Weibull, é possível predizer a estrutura de florestas tropicais que sofreram cortes seletivos. Entretanto, como as florestas tropicais são compostas por grande variação de espécies e tamanhos, as estimativas da distribuição podem ser melhoradas separando-se as espécies em grupos que tenham afinidades ecológicas e/ou econômicas. Esta informação ajudaria a monitorar a diversidade e dinâmica florística. 


\section{CONCLUSÕES GERAIS}

- As técnicas apropriadas para ajustar os parâmetros da distribuição dependem da eficiência estatística desejável e da capacidade computacional disponíveis (BAILEY \& DELL, 1973).

- Os métodos de Menon, Lindsay e Zanakis não estimaram satisfatoriamente DG e DM, sendo estes métodos não aconselháveis para estimarem estas variáveis. Entretanto Menon não apresentou diferença estatística (teste KS com nível de significância de 5\%) para nenhum distribuição diamétrica.

- O método da Máxima Verossimilhança mostrou ser o mais eficiente para estimar o DG e DM e a distribuição diamétrica, independente das situações estudadas. Esta performance foi seguida por Dubey, ainda que este não tenha sido tão eficiente.

- Ratificando a conclusão do trabalho de Bailey \& Dell (1973), nas situações estudadas, recomenda-se o uso do método da Máxima Verossimilhança quando há disponibilidade computacionais. Se não houver a disponibilidade, recomenda-se o uso do método de Dubey.

- Os modelos de regressão do sistema de predição dos parâmetros apresentaram coeficiente de determinação superiores aos valores citados por BAILEY et al., (1981). Uma novidade inseridas nas equações desenvolvidas foi a inclusão de variáveis que expressam a diversidade de espécies.

- Utilizando os parâmetros da função Weibull. os dois sistemas apresentaram boas estimativas de DG e DM. A qualidade do ajuste do diâmetro médio quadrático é importante, pois ele está relacionado com a área basal.

- O sistema de Recuperação dos Parâmetros foi um pouco superior ao de Predição, pois apresentou menor diferença significativa no teste KS e as amplitudes de DDM e 
DDG foram menores. Segundo BAILEY et al. (1981), a inferioridade do sistema de predição deve-se a variação introduzida através do processo de ajuste; estatísticas computadas diretamente dos dados podem ser mais predicáveis desde que não envolva nenhum processo de ajuste da curva.

- É possível predizer a estrutura de florestas tropicais que sofreram cortes seletivos, utilizando a função Weibull. Mas a estimação da estrutura diamétrica da comunidade não informa qual espécie poderá ser cortada. Uma sugestão é estudar a estrutura das espécie ou de grupos semelhantes nos diferentes tratamentos aplicados à floresta 


\section{REFERÊNCIAS BIBLIOGRÁFICAS}

ALDER, D. Growth modelling for mixed tropical forests. London: Nuffield Press, 1995. $231 \mathrm{p}$.

ARAUJO, P.A. Idade relativa como subsídio a determinação do ciclo de corte no manejo sustentável de povoamentos florestais nativos. Viçosa, 1993. 119p. Dissertação (M.S.) Universidade Federal de Viçosa.

BAILEY, R.L.; DELL, T.R. Quantifying diameter distributions with the Weibull Fuction. Forest Science, v.19, n.2, p.97-104, 1973.

BAILEY, R.L.; ABERNETHY, N. C. ; JONES Jr., E. P. Diameter distribution models for repeatedly thinned slash pine plantations. Washington: U.S.D.A, Forest Service, 1981. 32p. (General Technical, 34).

BARROS, P. C. de; MACHADO, S. A.; BURGER, D; SIQUEIRA, J. D. P. Comparação de modelos descritivos da distribuição diamétrica em uma floresta tropical. Revista Floresta, v.10, n.2, p. 19-32, 1981.

BATISTA, J.L.F. A função Weibull como modelo para a distribuição de diâmetros de espécies arbóreas tropicais. Piracicaba, 1989. 116p. dissertação (M.S.)- Escola Superior de Agricultura "Luiz de Queiroz", Universidade de São Paulo.

BATISTA, J.L.F. Spatial dynamics of trees in a brazilian atlantic tropical forests under natural and managed conditions. Seattle. 1994. 348p. Thesis (Ph.D.) University of Washington 
BUONGIORNO, J.; PEYRON, J.L.; HOULLIER, F.; BRUCIAMACCHIE, M. Growth amd management of mixed-species, uneven-aged forests in the French Jura: Implications for economic returns and tree diversity. Forest Science, v.41, n.3, p.397-429, Aug. 1995.

BURDEN, R.L.; FAIRES, J.D. Numerical analysis (4 ed.) Boston: PWS-Kent, 1985. 729p.

BURGER, D. Ordenamento florestal 1: a produção florestal. Curitiba: Fupef, 1980. 123p.

CAMPUS, J. C.; TURNBULL, K. J. Um sistema para estimar produção por classe de diâmetro e sua aplicação na interpretação de efeitos de desbaste. Revista Árvore, v.5, n.1, p. 1-16, 1981.

CLUTTER, J.E.; FORTON, J.C.; PIENAAR, L.V.; BRISTER, G. H.; BAILEY, R.L. Timber management: a quantitative approach. New York: Jonh Wiley, 1983.35 lp.

COHEN, A. C. Maximum likelihood estimation in the Weibull distribution based on complete and censored samples. Technometrics, v. 7, p.570-601, 1965.

DUBEY, S.D. Some percentile estimators for Weibull parameters. Technometrics, v. 9, n.1 p. 119-129, 1967.

FELFILI, J. M. Structure and dynamics of a Gallery Forest in Central Brazil. Oxford, 1993. 180p. Thesis (Ph. D)- University of Oxford.

GARCIA, A. Influência de diferentes niveis de exploração florestal em uma floresta tropical na região de Marabá Piracicaba, 1990. 201p. Dissertação (M.S.) - Escola Superior de Agricultura Luiz de Queiroz. Universidade de São Paulo.

HAPER, J. L. Population biology of plants. London: Academic Press, 1982. 892p.

HYINK, D. M.; MOSER, J. W. A generalized framework for projecting forest yield and stand structure using diameter distributions. Forest Science, v.29, n.1, p.85-95, 1983

JESUS, R.M. A reserva florestal da CVRD. Linhares: FRD, 1986, 29p.

JESUS, R. M.; COUTO, H. T. Z. do: GARCIA. A. Manejo florestal em Linhares 1- crescimento em função de diferentes niveis de intervenção. In: CONGRESSO NACIONAL SOBRE ESSÊNCIAS NATIVAS, 2O, São Paulo, 1992. Anais. São Paulo: Instituto Florestal, 1992. p.653-660. 
KURU, G. Simulation of thining effects on stand structure using co-ordinates. Australian Forestry, v. 55, p. 4-8, 1992.

LINDSAY, S.R.; WOOD G. R.; WOOLLONS, R. C. Stand table modelling through the Weibull distribution and usage of skewness information. Forest Ecology and Management, v.81, p.19-23, 1996.

LIU, C. M.; LEUSCHNER, W. A.; BURKHART, H. E. A production function of Loblolly Pine yield equations. Forest Science, v.35, n.3, 775-788, 1989.

MAcLEAN, C. D. Walk-through inventory: a short-cut substitute for remeasuring slow-growing inventory plots. In: Arid land resource inventories: developing cost-effective methods.Washington:Forest Service, 1978. p. 389-393.

MAGURRAN,A.E. Ecological diversity and its measurement Cambridge: University Press, 1988. 185p.

MENON, M.V. Estimation of the shape and scale parameters of the Weibull distribution. Technometrics, v.5, n. 2, p.175-182, 1963.

MEYER, H.A.; STEVENSON, D.D. The structure and growth of virgin beech-birch- maplehemlock forests in northen Pennsylvania. Jornal of Agricultural Research, v.67, n.15, p. $465-484,1943$.

MOSER, J. W. Dynamicis of na uneven-aged forest stand. Forest Science, v.18, p.184-191, 1972.

PIENAAR, L.V.: RHENEY, J.W. Yield prediction for mechanically site-prepared slash pine plantations in the southeastern coastal plain. Southern. Journal of Applied Forestry, v.17, n. 4, p.163-73, Nov.1993

RENNOLLS, D.: GEARY, D.N.; ROLLINSON, T.J. Characterizing diameter distributions by the use of the Weibull distribuiton. Forestry, v.58, n.1, p.58-66, 1985.

SARAIVA, C.L.M. Desenvolvimento de um método de manejo de mata natural mista pela utilização da distribuição de diâmetro. Viçosa, 1988, 11 p. Dissertação (M.S.)- Universidade Federal de Viçosa. 
SCOLFORO,J.R. Mensuracao florestal: crescimento florestal parte 2. Lavras: ESAL, FAEPE, 1995. 247p.

SCOLFORO, J.R.; MACHADO, S. do A. Um sistema de crescimento e produção com simulador de desbaste. Scientia Forestalis. N. 50 p. 51-94, dez. 1996

SHIVER, B. D. Sample size for estimating Weibull function parameters for Slash Pine plantations diameter distributions. Platation Management Reserch Cooperative, Technical Report, 1985, $21 \mathrm{p}$.

SILVA, J. A. Dynamics of stand structure in fertilized slash Pine plantations. Athens, 1986. 139p. Thesis (Ph.D.)- University of Georgia.

SOARES, P.; TOMÉ, M.; SKOWSGAARD, J.P.; VANCLAY, J.K. Evaluating a growth model for forests management using continuos forest inventory data. Forest Ecology and Management, v. 71 p.251-265, 1995.

SOKAL, R. R.; ROHLF, F. J. Biometry. New York: W. Freeman, 1995. 887p.

VANCLAY, J.K. Modelling forest growth and yield: application to mixed tropical forests. Oxon: CAB international, 1994. 330p.

ZAR, J. H. Biostatistical analysis. New Jersey: Prentice Hall, 1996, 615p.

ZARNOCH,S.J.: DELL,T.R. An evaluation of percentile and maximum likelihood estimators of weibull parameters. Forest Science, v.31, n.1, p.260-268. Mar.1985.

ZEIDE, B. Exponential diameter distribution: interpretation of coefficients. Forest Science, v.30, n.4, p.907-912, 1984.

ZEIDE,B. Analysis of growth equations. Forest Science, v.39, n.3, p.594-616, Ago. 1993.

ZUTTER,B. R.; ODERWALD, R. G.: MURPHY, P. A.: FARRAR, R. M. Characterizing diameter distributions with modified data types and forms of the weibull distribution. Forest Science, v.32, n.1, p.37-48, Mar. 1986. 